\title{
Scaling seismic fault thickness from the laboratory to the field
}

\author{
Thomas P. Ferrand ${ }^{1,2,3 *}$, Stefan Nielsen ${ }^{4}$, Loïc Labrousse ${ }^{5}$, Alexandre Schubnel ${ }^{6}$ \\ 1: Institut des Sciences de la Terre d'Orléans, CNRS UMR 7327, Université d’Orléans, France; \\ 2: Institute of Geophysics \& Planetary Physics, Scripps Institution of Oceanography, UC San Diego, La Jolla, USA; \\ 3: Earthquake Research Institute, University of Tokyo, Bunkyo-ku, Tokyo, Japan; \\ 4: Department of Earth Sciences, Durham University, Durham DH1 3LE, United Kingdom; \\ 5: Sorbonne Université, CNRS-INSU, Institut des Sciences de la Terre Paris, UMR 7193, Paris, France; \\ 6: Laboratoire de Géologie, CNRS UMR 8538, Ecole Normale Supérieure, PSL Research University, Paris, France. \\ *Corresponding author: thomas.ferrand@uni-orleans.fr
}

\begin{abstract}
Pseudotachylytes originate from the solidification of frictional melt, which transiently forms and lubricates the fault plane during an earthquake. Here we observe how the pseudotachylyte thickness $a$ scales with the relative displacement $D$ both at the laboratory and field scales, for measured slip varying from microns to meters, over six orders of magnitude. Considering all the data jointly, a bend appears in the scaling relationship when slip and thickness reach $\sim 1 \mathrm{~mm}$ and $100 \mu \mathrm{m}$, respectively, i.e. $M_{\mathrm{w}}>1$. This bend can be attributed to the melt thickness reaching a steady-state value due to melting dynamics under shear heating, as is suggested by the solution of a Stefan problem with a migrating boundary. Each increment of ult is heating up due to fast shearing near the rupture tip and starting cooling by thermal diffusion upon rupture. The building and sustainability of a connected melt layer depends on this energy balance. For plurimillimetric thicknesses $(a>1 \mathrm{~mm})$, melt thickness growth reflects in first approximation the rate of shear heating which appears to decay in $D^{-1 / 2}$ to $D^{-1}$, likely due to melt lubrication controlled by melt + solid suspension viscosity and mobility. The pseudotachylyte thickness scales with moment $M_{0}$ and magnitude $M_{\mathrm{w}}$; therefore, thickness alone may be used to estimate magnitude on fossil faults in the field in the absence of displacement markers within a reasonable error margin.
\end{abstract}

This article has been accepted for publication and undergone full peer review but has not been through the copyediting, typesetting, pagination and proofreading process, which may lead to differences between this version and the Version of Record. Please cite this article as doi: 10.1029/2020JB020694.

This article is protected by copyright. All rights reserved. 


\section{Introduction}

Originally evidenced in quartz-bearing rocks (Shand, 1916; Philpotts, 1964) and for large earthquakes (McKenzie \& Brune, 1972), frictional melting of the fault surface at depth is a common phenomenon (e.g. Toyoshima et al., 1990; Kanamori et al., 1998; Otsuki et al., 2003; Hirose \& Shimamoto, 2005a; 2005b; Spray et al., 2010; Beeler et al., 2016; Ferrand et al., 2017; Aubry et al., 2018). The result of this melting and fast quench is the formation of pseudotachylytes (e.g. Shand, 1916; Sibson, 1975; Ueda et al., 2008; Obata \& Karato, 1995; Andersen \& Austrheim, 2006; Andersen et al., 2014; Deseta et al., 2014a, 2014b). Located both in the fault vein and injection veins, they consist of either glassy or cryptocrystalline rocks (e.g. Toyoshima, 1990; Lin, 1994; Dobson et al., 2018; Ferrand et al., 2018) originating from the solidification of the frictional melt (Sibson, 1975), along with clasts remaining from the host rock. Pseudotachylytes have also been described as the result of landslides (Masch et al., 1985) and meteoritic impacts (Dietz, 1961; Wilshire, 1971), which are not the topic of the present study. An alternative

mechanism has been proposed to explain the formation of pseudotachylytes through intense comminution leading to slow mechanical amorphization (e.g. Wenk, 1978; Pec et al., 2012; Hayward et al., 2016; Marti et al., 2020), which is unlikely when either asymmetrical damage/injection (e.g. Griffith et al., 2012; Ferré et al., 2015; Thomas et al., 2017; Petley-Ragan et al. 2019) or fractionated crystallization (e.g. Warr \& van der Pluijm, 2005; Ferrand et al., 2018) are observed.

Alteration or retrograde metamorphism during the exhumation from great depth (up to $>80 \mathrm{~km}$ ) often affects the preservation of pseudotachylyte (e.g. Kirkpatrick et al., 2009; Kirkpatrick \& Rowe, 2013; Phillips et al., 2019). Nevertheless, pseudotachylyte remnants have been observed in various places around the world, especially within lower-crust and upper-mantle outcrops (e.g. Sibson et al., 1975; Obata \& Karato, 1995; Barker, 2005; Nielsen et al., 2010b; Di Toro et al., 2006; Andersen et al., 2014; Scambelluri et al., 2017). Rheological transitions and fluid-rock interactions tend to entirely transform the mineralogy on the

This article is protected by copyright. All rights reserved. 
fault itself but a significant part of the damage zone, containing millimetric and micrometric faults, can remain unaltered (e.g. Sibson, 1975; Scambelluri et al., 2017; Ferrand et al., 2018).

Comparing natural pseudotachylytes to their experimental analogues is key for understanding earthquakes mechanics (e.g. Di Toro et al., 2006). Laboratory studies have been reporting pseudotachylytes in various lithologies (Table 1; Table 2; Fig.1; Fig. 2), during rotary-shear experiments (e.g. Spray, 1987; Di Toro et al., 2006; Hirose \& Shimamoto, 2005a; Del Gaudio et al., 2009; Niemeijer et al., 2011), stick-slip experiments (e.g. Passelègue, 2014; Passelègue et al., 2016a; Brantut et al., 2016; Hayward et al., 2017; Lockner et al., 2017) and high-pressure experiments (Incel et al., 2017; Ferrand et al., 2017). Rotary-shear experiments have been able to reproduce "seismic" slip velocities (i.e. $\geq 1 \mathrm{~m} \cdot \mathrm{s}^{-1}$ ) and metric displacements characteristic of earthquakes of $M_{\mathrm{w}}>4$ (i.e. $D>2 \mathrm{~cm}$ ), providing data that scale with natural earthquakes (Nielsen et al., 2010b; Hirose \& Shimamoto, 2005b; Di Toro et al., 2011). Rotaryshear experiments shed new insights on the weakening mechanisms but explain only the frictional part of the seismic process, i.e. they do not include dynamic propagation, and are undertaken at normal stresses that are far lower than would be expected at earthquake hypocentres. Stick-slip experiments encompass both the seismic rupture nucleation and propagation stages (Passelègue et al., 2016a; 2016b; Aubry et al., 2018; Marty et al., 2019) but remain limited by the millimetric to pluricentimetric size of the sample, so that the laboratory magnitudes rarely exceed $M_{\mathrm{w}}-3$ (Passelègue et al., 2016a). In consequence, connecting laboratory results with seismological and field observations remains difficult and controversial.

The moment magnitude $M_{\mathrm{w}}$ of an earthquake is directly related to the average displacement $D$ on the fault plane, which allows geologists to give reasonable estimates of $M_{\mathrm{w}}$ based on direct field observations. However, deep lithologies often exhibit a lack of clear displacement markers. Based on field measurements on pseudotachylytes in the Outer Hebrides, Scotland, Sibson (1975) showed that, at the field scale, the relationship between $a$ and $D$ follows a power law. However, field observations of pseudotachylyte thickness are to be considered carefully, because discrete accumulations of glassy or fine-grain material,

This article is protected by copyright. All rights reserved. 
either in pull-aparts, dilational jogs (e.g. Sibson, 1975) or tensile fractures (e.g. Di Toro et al., 2005; Ferrand et al., 2018) have to be fully documented for a thorough average thickness estimate. Earthquake scaling may help understand slip weakening mechanisms (Abercrombie \& Rice, 2005). Large and small earthquakes present striking similarities (e.g. Kita \& Ferrand, 2018; Ide, 2019; Brodsky, 2019) and appear to nucleate similarly (Ide, 2019; Abercrombie, 2019), which supports that laboratory analogues (e.g. Mw 6 , fault $=1 \mathrm{~mm}$; Ferrand et al., 2017) may be representative of natural processes (e.g. Mw 6+, fault $>1 \mathrm{~km}$; Ferrand et al., 2018). However, it is not clear which parameters control the evolution of small-scale ruptures into larger events. Understanding to what extent laboratory analogues of earthquakes are representative of larger-scale natural events is key for the current advances in earthquakes physics and earthquake magnitude prediction (Kilb \& Gomberg, 1999; Wyss, 2001).

Slip on a plane lubricated with a silicate melt depends on the effective thickness and continuity of the melt layer, and on the viscosity of the melt. In nature, however, faults are not planes. Initial fault geometry is controlled by pre-seismic creep and gouge evolution (e.g. Bayart et al., 2018) and significantly impacts fault rheology (e.g. Johnson et al., 2001; Nielsen et al., 2016; Romanet et al., 2018), as it may define the rock volume to be melted. Slip lubrication leads to an asperity-scale dynamic stress drop much higher than seismological values (e.g. Passelègue et al., 2016a). Geometrical heterogeneities should control the cumulative melt volume. Strong-motion studies show that the rise time, i.e. required for slip to occur, is significantly shorter than the overall rupture duration (Beroza \& Mikumo, 1996), which supports a "pulse" rupture type (Heaton, 1990).

Here, we compile a number of laboratory and field observations of pseudotachylyte thicknesses versus their associated displacements (Table 1; Table 2; Fig.1; Fig.2), for slip values ranging from $<10 \mu \mathrm{m}$ to $>$ $1 \mathrm{~m}$. Based on energy considerations, we investigate the possible scaling of pseudotachylyte thickness with displacement and moment magnitude. This may help understand why some small ruptures propagate into

This article is protected by copyright. All rights reserved. 
larger ruptures when other ruptures do not, and possibly provide magnitude estimates based on the pseudotachylyte thickness.

\section{Field and laboratory observations}

As illustrated in Fig. 1, several works have reported fault thickness $a$ and relative displacement $D$ since the observations of Sibson (1975). We compile documented $D$ and $a$ data (Fig. 2) from both natural and experimental earthquakes, deriving from various geodynamic contexts (e.g. mantle vs. crust) or experimental techniques (e.g. stick-slip, rotary shear and D-DIA; Table 1).

\subsection{Data compilation}

Both field observations (e.g. Sibson, 1975; Ueda et al., 2008; Obata \& Karato, 1995; Andersen \& Austrheim, 2006; Nielsen et al., 2010a; 2010b; Andersen et al., 2014; Scambelluri et al., 2017; Ferrand et al., 2018) and laboratory analogues (e.g. Passelègue et al., 2016a; Incel et al., 2017; Brantut et al., 2016; Ferrand et al., 2017; Aubry et al., 2018) have revealed that the displacement $D$ is closely related to the thickness $a$ of fault veins.

Friction - until melting temperature is reached - and subsequent viscous shear in the molten layer provide a heat source, which is counteracted by the latent heat of melting $H$, the thermal diffusion into the country rock, depending on its heat capacity $C_{P}$, and advection with the loss of melt toward lateral tensile cracks or zones of dilation (i.e. jogs or stepovers). In the following, we note $w$ the average melt volume per unit fault surface (including the injection veins, e.g. Di Toro et al. 2011) and $a$ the residual thickness after melt injects in the cracks of the damage zone. If such injection is more frequent for large pseudotachylytes $(w>1 \mathrm{~mm})$ than for small pseudotachylytes $(w<1 \mathrm{~mm})$, then we may see a discrepancy where $a<w$ for the former and $a \sim w$ for the latter (Fig. 1a).

In Fig. 2 the log-log plot shows different log-linear trends and a break in slope $(D \approx 1 \mathrm{~mm}, a \approx 100$ $\mu \mathrm{m}$ ) suggesting a change in thermal or hydraulic regime of the dynamic system. Except for Barker (2005)

This article is protected by copyright. All rights reserved. 
and Di Toro et al. (2006), large-scale data, i.e. $D>1 \mathrm{~mm}$ and $a>100 \mu \mathrm{m}$, show a relatively close fit to the power law described by Sibson (1975):

$$
D=\beta \cdot a^{2}
$$

where $\beta=43600 \mathrm{~m}^{-1}$. On the other hand, for $D<1 \mathrm{~mm}$ and $a<100 \mu \mathrm{m}$, the data deviate from the loglinear trend of eq. (1). Note that the discrepancy between $w$ and $a$ is not sufficient to account for the bend at $a \sim 1 \mathrm{~mm}$. For example, if the scaling observed at the sub-metric scale was valid at a larger scale, the Balmuccia HP pseudotachylyte $(1.6<D<1.9 \mathrm{~m} ; a \approx 5 \mathrm{~mm}$; Ferrand et al., 2018) should have an effective thickness $w \approx 1 \mathrm{~m}$. There is no trace of such abundance of melt at the outcrop scale; in addition, according to first-order calculations the magnitude associated to $w \approx 1 \mathrm{~m}$ would be larger than 9 .

The data from Sibson (1975) and most data from Barker (2005) are apparent offset only, since displacement markers were not systematically identified on an exposed surface parallel to the slip direction. Theoretically, an offset $S$ corresponds to a true displacement $D=[S ; \propto[$. The large datasets of Nielsen et al. (2010b) and Di Toro et al. (2006) correspond to true displacement data, i.e. taking into account the geometry of the fault and the observed finite offset. Regarding the fault network from Scambelluri et al. (2017), the metagabbro sample was cut perpendicular to shear, which means that the observed offsets are true displacements with a negligible error. Regarding the HP fault described by Ferrand et al. (2018), the average apparent offset is $\approx 1.2 \mathrm{~m}$ for the main slip surface, which corresponds to a displacement of $1.75 \pm 0.15 \mathrm{~m}$, i.e. $\approx 45 \%$ larger than the measured offset. Considering that the rest of the dataset (red crosses, Fig. 2) follows the same offset-displacement relationship, a small uncertainty is taken into account (very small in log-log). For other field studies (Obata \& Karato, 1995; Andersen et al., 2014), only few displacement values are provided, which we associate with uncertainties of $+50 \%$.

Only a few studies (Di Toro et al., 2005; 2006; Pittarello et al., 2008; Ferrand et al., 2018) report the average thickness of pseudotachylytes measured over several meters of fault length. For the other studies, estimates can still be cautiously considered, either regarding the large number of data collected on the

This article is protected by copyright. All rights reserved. 
fault network (e.g. Nielsen et al., 2010b) or taking into account the internal consistency of the dataset (e.g. Barker, 2005). 3D photogrammetry for instance, will definitely allow future studies on pseudotachylytes to reach a sounder statistical approach, including the determination of the actual volume and 3D distribution of pseudotachylyte networks. Regarding the study of Obata \& Karato (1995), only the minimum and maximum values of a range of observed thicknesses is provided, which we tentatively associate in Fig. 2 with the associated displacement estimate of $\approx 3 \mathrm{~m}$. Rotary-shear experiments constitute the most reproducible experimental dataset of seismic slip (e.g. Hirose \& Shimamoto, 2005a; 2005b; Di Toro et al., 2006; Violay et al., 2015) and is for now the only technique reaching slip value typical of natural earthquakes with $\mathrm{Mw}>4(>2 \mathrm{~cm})$. In particular, this technique evidences dynamic friction values approaching zero during melt lubrication (Di Toro et al., 2004). However, in rotary-shear experiments, the slip surface is not confined within a larger sample (D-DIA experiments for instance) or a jacket (stick-slip experiments). Melt is therefore easily extruded, leading to much smaller final melt thickness ( $a^{*}$; Fig. 2;

Table 2). Nonetheless, some publications provide a record of the axial shortening during rotary-shear experiments (Di Toro et al., 2006; Niemeijer et al., 2011), which actually relates to the cumulative melt (+ clasts) thickness ( $w^{*}$; Fig. 2; Table 2).

Regarding other experimental studies, the observations correspond to displacement as long as the samples are cut perpendicular to the fault and the uncertainty mostly relies on the "single-jerk" assumption, especially for the stick-slip design (section 4.1). Based on a limited number of FIB sections, DDIA studies consistently report values of some tens of nanometers. Values as small as $20 \mathrm{~nm}$ are associated to local larger amorphous pockets along the fault, up to $200 \mathrm{~nm}$ thick (Ferrand et al., 2017).

\subsection{Scaling of pseudotachylyte thickness under the adiabatic assumption}

Considering the rock volume enduring frictional heating as a closed system within a very short timescale, the adiabatic assumption can be considered (Sibson \& Toy, 2006; Rempel \& Rice, 2006). For each increment of rock on the rupture path, the duration of shear is extremely short (Heaton, 1990; Beroza

This article is protected by copyright. All rights reserved. 
\& Mikumo, 1996), i.e. not the full slip timescale but the timescale of the initial shear and rupture. In other words, the local onset of efficient melt lubrication, which favors slip, actually corresponds to the local onset of cooling. Such short timescales also imply undrained conditions likely applying to the dynamic melt layer, at least for small events $(w<1 \mathrm{~mm})$.

Assuming a Newtonian melt, negligible fracture energy and negligible viscoelastic effects (section

4.2), the total shear heating $Q$ results from the time integral of shear power (Nielsen, 2008):

$$
Q=\int_{0}^{t} \tau\left(t^{\prime}\right) \cdot V\left(t^{\prime}\right) \cdot d t^{\prime}=\int_{0}^{t} \tau\left(D^{\prime}\right) \cdot \frac{d D}{d t^{\prime}} \cdot d t^{\prime}=\int_{0}^{D} \tau \cdot\left(D^{\prime}\right) \cdot d D^{\prime}=\bar{\tau} \cdot D
$$

with $\bar{\tau}$ the average shear stress during the slip $D$ at a velocity $V$. The heat $Q$ can be partitioned into specific heat, latent heat for phase transitions (e.g. melt) and other heat sinks (e.g. diffusion, melt extraction).

Considering an adiabatic pseudotachylyte formation (Sibson 1975), all the heat $Q_{\mathrm{a}}$ generated in the process zone is dissipated within the molten layer on the rupture timescale and is directly related to its thickness $w_{\mathrm{a}}$ :

$$
Q_{\mathrm{a}}=\bar{\tau} \cdot D=\rho \cdot\left(C_{P} \cdot \Delta T+H\right) \cdot w_{\mathrm{a}}
$$

with $H$ the latent heat of fusion, $\rho$ the density, $C_{p}$ the heat capacity and $\Delta T=\left(T_{m}-T_{i}\right)$ the process-zone heating during the dynamic rupture propagation $\left(T_{m}\right.$ : melting point; $T_{i}$ : initial host-rock temperature). This implies that the thickness of the molten layer is a linear function of $D$ as follows:

$$
w_{\mathrm{a}}=A_{1} \cdot D
$$

with $A_{1}=\bar{\tau} /\left[\rho \cdot\left(C_{P} \cdot \Delta T+H\right)\right]$. As shown on Fig. 2, $w_{\mathrm{a}}$ strongly depends on $\bar{\tau}$. Assuming that $H=0.3$ $\mathrm{MJ} \cdot \mathrm{K}^{-1}, \rho=3000 \mathrm{~kg} \cdot \mathrm{m}^{-3}, C_{p}=1 \mathrm{~kJ} \cdot \mathrm{kg}^{-1} \cdot \mathrm{K}^{-1}$ and $\Delta T=1000 \mathrm{~K}$ then $A_{1} \approx 3.10^{-3}$ for $\bar{\tau}=10 \mathrm{MPa}$.

The adiabaticity is satisfied if $w$ is larger than the heat diffusion distance within the duration of the slip $(w \gg \sqrt{\pi \cdot \kappa \cdot t}$ ). However, $w$ is dynamically growing during the slip, and the ratio $w / t$ is not necessarily constant throughout the spectrum of observed vein sizes.

This article is protected by copyright. All rights reserved. 
Looking at the entire dataset, the adiabatic scaling reproduces the observations pretty well (Fig.2). This is particularly true at small scale $(D<1 \mathrm{~mm})$, because of small associated time scales (10 to $1000 \mu \mathrm{s}$ only), during which sliding is likely to occur under quasi-adiabatic and undrained conditions.

On the contrary, at a larger scale $(D>10 \mathrm{~mm})$, melt can advect and temperature diffuse, to such an extent that the effective thickness $w$ of the silicate melt layer increases less with sliding (Passelègue et al., 2016b). Effects of both temperature diffusion and melt advection should depend on time and space scales, respectively via thermal diffusivity and melt viscosity. Notably, the concept of "seismic suction pump" was proposed to explain near-fault drops of fluid pressure during rupture propagation (Sibson, 1987) and has recently been confirmed in laboratory experiments producing stick-slip events systematically associated with near-instantaneous drops in fluid pressure (Brantut et al., 2020). This effect has been extended to the mobility of the rupture-induced transient melt observed at high pressure (Ferrand, 2017; Ferrand et al., 2018). The link observed by Sibson (1975) between $D$ and $a$ could be the result of a combination of the dynamic rupture process, as observed in the laboratory (e.g. Passelègue et al., 2016a) and of melt sucking in tension cracks (Ferrand, 2017). Thus, the deviation in the pseudotachylyte scaling law could be interpreted as due to both scale-dependent heat conduction and melt pumping effects. Therefore, in section 3 we remove the adiabatic assumption.

\section{Pseudotachylyte formation with heat diffusion}

The bend observed in the scaling law can be attributed to the effect of melting dynamics under shear heating at large scales. At first order, the dataset seems to follow the adiabatic trend (eq. (4)) at small scales $(D<1 \mathrm{~mm})$ and Sibson's empirical law (eq. (1)) at larger scales (Fig.2). Separating the dataset between low confining pressures (<0.5 GPa; Fig.3) from high confining pressures ( $>0.5 \mathrm{GPa}$; Fig.4), the intersection/transition from eq. (4) and eq. (1) appears less well defined, for several reasons discussed

This article is protected by copyright. All rights reserved. 
later (section 4.1). Nevertheless, at high pressures, linking experimental and field data clearly highlight a discrepancy between $D<1 \mathrm{~mm}$ and $D>1 \mathrm{~mm}$ (Fig.4).

To better understand the apparent discrepancy between small-scale and large-scale observations, it is important to come back to the definition of the seismic rupture, which is the dynamic migration of a mechanical instability (e.g. Ohnaka, 2003; Passelègue et al., 2016a), thus implying a migration boundary of the melt front. The full problem of melting coeval with heat diffusion requires solving a Stefan problem, where the heat balance is defined at the advancing melt front (Carslaw \& Jaeger, 1959; Nielsen et al., 2008). In section 3.1, we develop the model, whose results in section 3.2 show that the key is in the first moments of the sliding and that Sibson's empirical law differs from the adiabatic model (section 2.2) for large events in case of inefficient lubrication.

\subsection{Stefan problem: heat balance at the advancing melt front}

Following Nielsen et al. (2010b), a Crantz-Nicolson finite difference scheme is used to numerically solve the 1-D diffusion equation with an advection term, coupled to the boundary condition:

$$
\rho \cdot H \cdot v=\kappa \cdot \rho \cdot C_{p} \cdot\left(\left.\frac{\partial T}{\partial z}\right|_{+}-\left.\frac{\partial T}{\partial z}\right|_{-}\right)
$$

The +/- signs refer to the heat flow at the melting front toward the rock and toward the melt, respectively, and $v$ is the advancement velocity of the melting boundary, i.e. the boundary between melt and country rock.

For simplicity we assume that density and diffusivity are the same in either melt or solid phases, and constant. It can be shown (Nielsen et al. 2010) that:

$$
\left.\frac{\partial T}{\partial z}\right|_{-} \approx \frac{\tau(t) \cdot V(t)}{2 \cdot \kappa \cdot \rho \cdot C_{p}}
$$

resulting in:

$$
\rho \cdot H \cdot v=\left.\kappa \cdot \rho \cdot C_{p} \cdot \frac{\partial T}{\partial z}\right|_{+}+\frac{1}{2} \cdot \tau(t) \cdot V(t)
$$

This article is protected by copyright. All rights reserved. 
A nearly steady-state situation can be achieved after an initial transient, provided that $\tau \cdot V$ changes gradually. In such case $\left.\frac{\partial T}{\partial z}\right|_{+}=\frac{-v}{\kappa} \cdot \Delta T$ (Nielsen et al., 2008) and eq. (7) reduces to:

$$
v(t)=\frac{\tau(t) \cdot V(t)}{2 \cdot \rho \cdot\left(H+C_{P} \cdot \Delta T\right)}
$$

Importantly, time integration of eq. (8) yields eq. (4), indicating that the steady-state replicates the adiabatic situation. Indeed, the heat loss through diffusion is retrieved when the melting boundary advances, thus resulting in no net loss in steady-state. However, an initial transient can be predicted based on dimensional considerations and simple analytical solutions of the diffusion equation (Nielsen et al., 2008, eq. 24) where no steady-state has yet been reached:

$$
D_{c}=8 \cdot \frac{\tau}{V} \cdot\left(\frac{\rho \cdot\left(H+C_{P} \cdot \Delta T\right)}{\tau}\right)^{2}
$$

Substituting $\tau=500 \mathrm{MPa}, V=1 \mathrm{~m} / \mathrm{s}, \Delta T=1000 \mathrm{~K}$ and peridotite parameters in eq. (9) we obtain $D_{c}=0.59 \mathrm{~mm}$, in agreement with $D_{c} \approx 0.1-1 \mathrm{~mm}$ in Fig. 4.

\subsection{Modelling results}

For sake of clarity, solutions of the Stefan problem are given and compared to observational data separating low $(\mathrm{P}<0.5 \mathrm{GPa})$ and high-pressure $(\mathrm{P}>0.5 \mathrm{GPa})$ events, respectively in Fig. 3 and Fig. 4. No steady-state is assumed in these models, where we use eq. (7) to obtain the velocity $v$, and a numerical solution of the diffusion equation to obtain the term $\left.\frac{\partial T}{\partial z}\right|_{+}$(Nielsen et al., 2010b). The melt volume per unit fault surface is thereafter obtained by $w(t)=\int_{0}^{t} v\left(t^{\prime}\right) d t^{\prime}$.

A time-dependent heat source $\tau(t) \cdot V(t)$ is imposed and the resulting $w(t)$ is compared to the observed pseudotachylyte thickness $w(D)$ (gray curves, Fig. 3 and Fig. 4) under the assumption that $w(D)=w(V \cdot t) ; V=1 \mathrm{~m} \cdot \mathrm{s}^{-1}$. We use values of $H, \rho, C_{p}$ and $\kappa$ which are broadly relevant for the variety of cases discussed here, but more closely related to peridotite.

This article is protected by copyright. All rights reserved. 
We test the model using a trial heat which remains relatively high and approximately constant during a very short initial slip stage where $\tau \cdot V=q_{0}$, subsequently switching to of the form $\tau \cdot V=q_{0} \cdot \sqrt{\frac{D_{c}}{D}}\left(q_{0}\right.$ constant in $\mathrm{J} \cdot \mathrm{m}^{-2} \cdot \mathrm{s}^{-1}$ ) in agreement with high-velocity weakening observed in rotary-shear experiments (Nielsen et al., 2016) and with the fit initially proposed by Sibson (1975). To further support such choice for $\tau \cdot V$, we note that high-velocity friction can be fitted (Nielsen et al. 2016) by $\tau \propto 1 / \sqrt{D}$, resulting in $\bar{\tau} \cdot D \propto \sqrt{D}$. For slip velocity during experiments and earthquakes, we may assume an indicative slip history with an initial acceleration $\alpha$ of slip such that $V=\alpha \cdot t=\sqrt{2 \cdot D \cdot \alpha}$ up to a critical distance $D_{c}$, followed by a modest variation such that $V \approx$ Const $\approx \sqrt{2 \cdot \alpha \cdot D_{c}}$, resulting in an initial heat power $\tau \cdot V \propto \sqrt{2 \alpha} \propto$ $q_{0}$, followed by $\tau \cdot V \propto \sqrt{\frac{D_{c}}{D}}$.

The gray curves in Fig. 3 and Fig. 4 are obtained from modelling with $q_{0}=500 \cdot 10^{6} \mathrm{~J} \cdot \mathrm{m}^{-2} \cdot \mathrm{s}^{-1}$ (as an indication, this value is compatible with $V=1 \mathrm{~m} \cdot \mathrm{s}^{-1}$ and $\tau=\mu \cdot \sigma_{n}=0.5 \times 1 \mathrm{GPa}$, and it is assumed that the volume loss by injection is relatively limied therefore $a \approx w)$. Three different values were modelled for the onset of weakening: [1] $t_{c}=7.55 \cdot 10^{-6}$ s (i.e. $D_{c}=2.88 \cdot 10^{-5} \mathrm{~m}$; corresponding to the onset of melting at $T=T_{m}$ ), [2] $t_{c}=10^{-3} \mathrm{~s}$ and [3] $t_{c}=\infty$ (the latter case results in a constant power $q_{0}$ throughout the slip; arguably, this may account for absence of weakening due to high viscosity of colder or more felsic melt, to match the datapoints in the higher part of the diagram).

In all three cases the initial thickness is relatively low, in agreement with D-DIA datapoints, but rapidly increases because the melting front is still in the initial transient stage. At about $D \approx 0.1-1 \mathrm{~mm}(a \approx$ $\left.10^{-4} \mathrm{~m}\right)$ a quasi-steady-state is reached where thickness increases as $\propto \sqrt{D}$ in agreement with the imposed power which decays in $\approx 1 / \sqrt{D}$ for curves [1] and [2], therefore closely matching the steadystate/adiabatic approximation of eq. (6). For case [3] the thickness increases as $\propto D$ again in agreement with the steady-state approximation of eq. (6) but assuming that the power is roughly constant throughout the slip.

This article is protected by copyright. All rights reserved. 
Once the steady-state thickness is reached $\left(D>D_{c}\right)$, we retrieve the trend compatible with Sibson's observation such that $w_{\mathrm{SS}}=\mathrm{A}_{2} \cdot D^{1 / 2}$ with $\mathrm{A}_{2}=\sqrt{1 / \beta} \approx 5 \cdot 10^{-3} \mathrm{~m}^{1 / 2}$, in agreement with stress decay $\bar{\tau} \propto$ $1 / \sqrt{D}$

As mentioned above, Barker (2005) and Di Toro et al. (2006) reported large-scale pseudotachylytes that do not follow Sibson's law, but rather a linear relationship between $D$ and $a$, suggesting an adiabatic process and inefficient melt lubrication. The data of Barker (2005) indicate $\bar{\tau}>100 \mathrm{MPa}$ when the data of Di Toro et al. (2006) would indicate $\bar{\tau} \approx 10 \mathrm{MPa}$ (Fig. 2). Contrary to all other studies focusing on isotropic rocks, Barker (2005) describes pseudotachylytes in a quartzo-feldspathic schist, suggesting that the bend is host rock-dependent. The parameters controlling melting point and magma viscosity, and how the latter influence our modelling results, are discussed in section 4.2. In any case, according to our modelling results, Sibson's empirical law actually corresponds to efficient melt lubrication case, while scaling relations closer to the adiabatic (linear) trend correspond to events where weakening was not significant.

\section{Discussion}

The results presented in section 3.2, if carefully considered in light of limitations of both the dataset (section 4.1) and the model (section 4.2), might yield a tool to estimate the magnitude of an earthquake by simply looking at the thickness of the resulting pseudotachylyte (section 4.3).

\subsection{Limitations of the dataset}

Displacement-thickness or offset-thickness datasets are presented along with associated uncertainties (section 2; Fig.2). Here we detail, separately, the factors likely to control displacement and thickness.

Displacement estimates depend on the experimental design: for the D-DIA experiments, several lines of evidence suggest that each transformation-induced fault records a single seismic event (Schubnel et al., 2013; Ferrand et al., 2017; Incel et al., 2017), which is uncertain for stick-slip experiments that give an

This article is protected by copyright. All rights reserved. 
estimate at the scale of the saw-cut after seismic events (Passelègue et al., 2016a; Brantut et al., 2016; Aubry et al., 2018). This could actually explain why displacements are up to one order of magnitude larger in stick-slip experiments compared to faults with the same thickness in the D-DIA (Fig. 2), even though differences in machine stiffness may also be at play. Considering multiple pseudotachylyte generation on the same fault plane, a significant increase of $D / a$ would be observed. However, publications highlight the high strength of faults welded by pseudotachylyte (Di Toro \& Pennacchioni, 2005; Mitchell et al., 2016; Proctor \& Lockner, 2016; Hayward \& Cox, 2017). Thus, new ruptures are not expected to affect preexisting pseudotachylytes except for stick-slip experiments or in case of alteration. In nature, pseudotachylytes may also form from shear zones exhibiting a significant displacement before rupture nucleation (e.g. Sibson, 1980; Chattopadhyay et al., 2008; Pittarello et al., 2012, John et al., 2009), but no evidence of it has been reported in the reviewed studies (Fig. 2). Notably, either local mylonites or cataclasites on the side of a pseudotachylyte network can be coeval with the pseudotachylyte (e.g. horse-tail termination, Ferrand et al., 2018; cataclastic damage zone, Petley-Ragan et al., 2018). Such coeval evolution highlights the key role of the strain rate (variable in time and space) and has been reported in both field and experimental studies (e.g. Fabbri et al., 2000; Kim et al., 2010).

The thickness $a$ measured in the field may vary over more than one order of magnitude along strike, either due to dilational and contractional jogs or because of melt flux into the damage zone (e.g. Sibson, 1975; Ferrand et al., 2018). Field studies show that pseudotachylytes might be present as discontinuous patches along a fault, with melting only along contractional jogs (Griffith et al., 2009; Kirkpatrick \& Shipton, 2009). Experimental data also show significant variation of the pseudotachylyte thickness (e.g. Hayward \& Cox, 2017). For stick-slip experiments, only cumulative average values are available. For D-DIA experiments, TEM on FIB sections is required to measure the fault thickness. In rotary-shear experiments, the sample is only meant to be an equivalent of a limited fraction of a fault, while other techniques may encompass complete fractures, i.e. ruptures area smaller than the sample size. In addition, the

This article is protected by copyright. All rights reserved. 
experimental fault segment is not confined, which induces fast extrusion of the melt out of the fault plane. Finally, rotary-shear experiments do not reproduce dynamic ruptures but slip generated artificially by a motor, although it provides the dynamic molten layer extrusion (section 2.1). For normal stress larger than $20 \mathrm{MPa}$ and abrupt accelerations to target slip rates of $3 \mathrm{~m} \cdot \mathrm{s}^{-1}$, rotary-shear data are well fitted by the model presented in section 3 (Fig. 2; Niemeijer et al., 2011).

\subsection{Limitations in the physical model}

The occurrence and efficiency of melt lubrication depend on the melting point and melt viscosity, which are not explicitly taken into account in our model (section 3). However, these key factors are implicitly contained within the characteristic time $t_{\mathrm{c}}$ and associated distance $D_{\mathrm{c}}$ (onset of weakening). Studies reporting pseudotachylyte thickness and displacement data investigate various lithologies and contexts

(Fig. 1, Fig. 2, Table 1), but the same physics should apply. In the same conditions of pressure, temperature, stress and strain rate, similar materials rupture in the same way. Hereafter we discuss the influence of rock composition, pressure, temperature and strain rate on the melting point and melt viscosity.

Melt viscosity is linked to rock chemistry and temperature (e.g. Taniguchi, 1992; Spray, 1993; Suzuki, 2001). Between 1500 and $2000^{\circ} \mathrm{C}$ at 1 atm, ultramafic melts are at least one order of magnitude less viscous than crustal melts with higher silica contents (Holtz et al., 1999; Karki et al., 2013). At $1800^{\circ} \mathrm{C}$, a melt of $\mathrm{MgO}$ or $\mathrm{Mg}_{2} \mathrm{SiO}_{4}$ composition exhibits a viscosity six orders of magnitude lower than $\mathrm{SiO}_{2}$ (Karki et al., 2013). Melt viscosity is primarily governed by $\mathrm{SiO}_{2}$ tetrahedra polymerization, strongly limited by cation diversity (e.g. Whittington et al., 2000; Le Losq et al. 2013; Toplis \& Dingwell, 2004).

The viscosity of silicate melts decreases with pressure (e.g. Gupta, 1987; Xue et al., 1991; Bottinga \& Richet, 1995; Suzuki et al., 2002; Liebske et al., 2005) due to a change in silicon coordination (Xue et al., 1991). The viscosity of dacite or albite melts drops by one order of magnitude when the pressure increases by 2 GPa (Tinker et al., 2004). These factors contribute to a drastic reduction of the melt viscosity at depth. Peridotitic melts may have a viscosity as low as 1 Pa.s at ambient pressure (Dingwell et al., 2004), which

This article is protected by copyright. All rights reserved. 
drops to $\sim 10^{-1}$ Pa.s between 1 and 3 GPa (Suzuki et al., 2001; Liebske et al., 2005), equalling diopside viscosity (Taniguchi, 1992), whereas higher $\mathrm{SiO}_{2}$ contents (e.g. andesite composition) exhibit viscosities of 10 Pa.s (Vetere et al., 2006).

At high slip rates, displacement is accommodated over finite distances with extremely high strain rates, i.e. far above the conditions for viscoelasticity. Whether a melt behaves as a solid or a liquid depends on its relaxation time (Dingwell \& Webb, 1989; Hayward et al. 2019). Most geological materials have nonNewtonian viscosities, especially strain-rate dependent. For seismic slip and at temperatures above the melting temperature, this could result in viscosities being many orders of magnitude less than standard laboratory measurements (Webb \& Dingwell, 1990). In addition, a moderate solid fraction may increase the viscosity of the solid+melt suspension by one order of magnitude (Costa, 2005; Ferrand et al., 2018). The solid fraction is likely to be high in rocks made of minerals with very different melting point (e.g. tonalite; Di Toro et al., 2006), whereas peridotites likely endure congruent melting (Ferrand et al., 2018). Furthermore, exothermic crystallization (Burbank, 1936; Blundy et al., 2006) may inhibit the viscosity decay.

Water, either aqueous or structurally bound, is key to activating weakening processes (e.g. Mei \& Kohlstedt, 2000a; 2000b; Violay et al., 2014). Dehydration reactions induce dynamic weakening that favors strain localization and seismic sliding (e.g. Brantut et al., 2008). Conversely, during sliding-induced antigorite dehydration, a pressurized low-viscosity silicate melt leads to extremely efficient lubrication (Brantut et al., 2016). In small amounts, water lowers the melting point of peridotite by $\sim 100{ }^{\circ} \mathrm{C}$, inducing olivine melting around $1300{ }^{\circ} \mathrm{C}$ (San Carlos, 0.32 wt.\% $\mathrm{H}_{2} \mathrm{O}$; Gaetani \& Grove, 1998). Water also drastically lowers melt viscosity (Kushiro et al., 1976; Richet et al., 1996; Vetere et al., 2006). As a consequence, tension cracks forming in the dilatant quadrant as rupture propagates (e.g. Okubo et al., 2019) generate transient depressions able to suck the melt out of the fault core (Ferrand et al., 2018). Inasmuch as melt viscosity is sufficiently low, the melt flux toward these cracks may also represent an important heat sink.

This article is protected by copyright. All rights reserved. 
The viscosity in the fault vein is expected to increase due to both extrusion (fault thinning) and enhanced quench (solidification). The suction effect dynamically migrates as long as there is still enough lubricant to propagate the rupture. Alternative lubrication mechanisms, such as thermal pressurization (Rempel \& Rice, 2006; Viesca \& Garagash, 2015) could play a significant role if melting conditions are not fulfilled.

As mentioned in section 3, the study of Barker (2005) reported a pseudotachylytes population with $D$ and $a$ consistent with adiabatic formation (section 2.3, Fig.2), indicating higher values of average shear stress $\bar{\tau}>100 \mathrm{MPa}$. According to eq. (3), this could also be due to a lower $\rho$, a lower $C_{P}$ or a lower $\Delta T$ (lower melting point). The data of Di Toro et al. (2006) are also consistent with the adiabatic assumption, which suggests that quartzo-feldspathic rocks would not achieve efficient weakening after the onset of melt-assisted lubrication. Feldspar has a lower melting point $\left(\sim 1500^{\circ} \mathrm{C}\right.$; Taniguchi, 1992 ; Suzuki et al., 2002) than the other minerals constituting the rocks of the dataset, but the high Si/Mg ratio maintains a relatively high melt viscosity at low pressure (< $0.5 \mathrm{GPa}$; Suzuki et al., 2001).

The Woodroffe Thrust fault zone (Australia, e.g. Camacho et al., 1995) appears as a counterexample for the scaling law proposed in this study. The fault zone is $\approx 1 \mathrm{~km}$ thick and contains $\approx 4 \%$ of pseudotachylyte veining. Large volumes of pseudotachylytes formed in anhydrous felsic granulites, but in significantly smaller volumes in underlying amphibolite-facies rocks (Camacho et al., 1995). The high Si content and the anhydrous conditions probably maintained a high melt viscosity, which means that a larger melt layer is required for a given amount of slip to account for the same stress drop. In addition, the zone is characterized by numerous seismic events, some of which potentially affecting the same fault segment, consistently with repeating earthquakes inferred by seismologists (Uchida \& Bürgmann, 2019).

\subsection{Implication: Moment magnitude vs pseudotachylyte thickness}

Keeping in mind the limitations detailed above, we can try a tentative scaling of the pseudotachylyte thickness with the earthquake magnitude. The stress drop $\Delta \tau$ during an earthquake is controlled by the fault geometry such that (Kanamori, 1977):

This article is protected by copyright. All rights reserved. 


$$
\Delta \tau=C \cdot \mu \cdot D / L
$$

with $L$ is the fault length and $\mu$ is the shear modulus, e.g. $\sim 8.10^{10} \mathrm{~Pa}$ for olivine, and $C$ is a geometrical constant $\approx 1$. The moment magnitude $M_{0}$ is defined as:

$$
M_{0}=\mu \cdot D \cdot L^{2}
$$

Combining (10) and (11), the displacement $D$ can be expressed as a function of $M_{0}$ as follows:

$$
D=\left(\frac{\Delta \tau}{C}\right)^{2 / 3} \cdot \frac{M_{0}^{1 / 3}}{\mu}
$$

As a consequence, for an adiabatic process, $w_{\text {adiab }}$ varies as $\sqrt[3]{M_{0}}$ :

$$
w_{\text {adiab }}=\left(\frac{\Delta \tau}{C}\right)^{2 / 3} \cdot \frac{M_{0}{ }^{1 / 3}}{\mu} \cdot A_{1}
$$

with $A_{1}=\bar{\tau} /\left[\rho \cdot\left(C_{P} \cdot \Delta T+H\right)\right]$, the thickness $w_{\text {adiab }}$ can be expressed as a function of $\Delta \sigma, \bar{\tau}$ and $M_{0}$ :

$$
w_{\text {adiab }}=\left(\frac{\Delta \tau}{C}\right)^{2 / 3} \cdot \frac{M_{0}^{1 / 3} \cdot \bar{\tau}}{\rho \cdot\left(C_{P} \cdot \Delta T+H\right) \cdot \mu}
$$

Considering large-scale steady-state, $w_{\mathrm{Ss}}$ varies as $\sqrt[6]{M_{0}}$ :

$$
w_{\mathrm{SS}}=\left(\frac{\Delta \tau}{C}\right)^{1 / 3} \cdot \frac{M_{0}^{1 / 6}}{\mu^{1 / 2}} \cdot A_{2}
$$

To summarize this subsection, $w_{\mathrm{adiab}}$ and $w_{\mathrm{Ss}}$ vary as $\sqrt[3]{M_{0}}$ and $\sqrt[6]{M_{0}}$ respectively. In other words, the pseudotachylyte thickness saturates for large earthquakes (Fig. 5) and cannot be much larger than 5 $\mathrm{cm}$, which corresponds to a Mw 9, i.e. tens of meters of slip. $\left(M_{w} 9\right)$. Hence, larger pseudotachylyte veins found on the field are likely to represent "injectites" (tension cracks), local pull-apart structures or the result of successive events.

We define the crossover moment $M_{0}{ }^{\mathrm{c}}$ as the intersection between the calculations considering adiabatic and non-adiabatic processes, that can be written:

$$
M_{0}{ }^{\mathrm{c}}=\left(\frac{C}{\Delta \tau}\right)^{2} \cdot\left(\frac{\rho \cdot\left(C_{P} \cdot \Delta T+H\right) \cdot \mu}{\bar{\tau}}\right)^{6} \cdot A_{2}{ }^{3}
$$

Keeping the same assumptions as for eq. (9), the crossover seismic moment $M_{0}{ }^{\mathrm{c}}$ would be around $5.10^{13}$ to $10^{14}$, i.e. $M_{w} \approx 3$, mostly depending on $\bar{\tau}$ and $\Delta \tau$ (Fig. 6). When $M_{0} \leq M_{0}{ }^{\mathrm{c}}$ measuring $w$ could provide a reasonable estimate of $M_{w}$, but for larger events efficient melt lubrication would induce

This article is protected by copyright. All rights reserved. 
significant uncertainties, with fault veins thicknesses of some millimeters potentially corresponding to magnitudes ranging from 2 to 7 . This implies that field observations of pseudotachylyte thickness should be used carefully in the establishment of energy balances. The total melt volume produced per surface unit appears much more adequate, which requires a thorough investigation at the outcrop scale to estimate the melt amount intruded within the damage zone. In the field, as large pseudotachylyte exposures are necessarily truncated for large events, it is only possible to give minimum estimates of either $D$ or $M_{w}$. Nonetheless, carefully considering all the parameters detailed in this study, notably compositional considerations and P-T conditions, some estimate could be made. Furthermore, in the absence of displacement marker at a large pseudotachylyte fault vein ( $a>1 \mathrm{~mm}$ ), studying the damage zone could give some idea of the size of the main rupture surface. Our model could be used to upscale small-scale observations for either adiabatic or diabatic ruptures.

\subsection{Implication: energy balance}

A recent study showed that the energy dissipated by fracturation during the propagation of the seismic rupture depends on the size of the asperities of the fault surface, following a power law (Passelègue et al., 2016b). The nucleation length directly depends on the fracture energy, which means that it depends on the asperity size (Ohnaka, 2003; Passelègue et al., 2016b). The energy balance of fault slip would suggest that fracture energy $G$ dissipates in fault weakening due to coseismic processes (including melting) that would reduce the heating. Seismological inferences of $G$ do show that in itself it is an increasing function of slip (e.g. Rice, 2006; Viesca \& Garagash, 2015).

Interestingly, the scaling relationship of $G$ with $D$ also shows a change of slope at $D \sim 1 \mathrm{~mm}$, varying as $D^{2}$ for $D<1 \mathrm{~mm}$ and as $D^{2 / 3}$ for $D>1 \mathrm{~mm}$ (Viesca \& Garagash, 2015). Furthermore, $D$ varies as $a^{2}$ for $D$ $>1 \mathrm{~mm}$, thus $G$ varies as $a^{4 / 3}$; and for $D<1 \mathrm{~mm} D$ may actually vary as $a^{2 / 3}$, which would mean that $G$ varies as $a^{4 / 3}$ as well. In other words, the pseudotachylyte thickness would scale with the fracture energy with no impact of scale.

This article is protected by copyright. All rights reserved. 


\section{Conclusions}

Pseudotachylyte thickness scales with slip over six orders of magnitude for measured slip varying from microns to meters, which can therefore be cautiously estimated in the field even in the absence of displacement markers. As a consequence, the thickness scales with moment $M_{0}$ and magnitude $M w$. Experimental and natural faults show striking similarities. Regardless of design, the scaling law follows the same trend. The bend observed in the scaling law is interpreted as the signature of pseudotachylyte thickness saturation for large $M w$ due to scale-dependent efficiency of melt-assisted lubrication and possibly to variations in viscosity and mobility of the pseudotachylyte met suspension infill. The thickness of the molten layer cannot be much larger than $5 \mathrm{~cm}$, which corresponds to a $M w$, i.e. tens of meters of slip. Hence, larger reported pseudotachylyte veins most likely correspond to injection veins or local dilational jogs along longer and thinner faults.

\section{Acknowledgments}

We thank Sarah Incel for providing the SEM image of the dehydrated lawsonite blueschist. This research is supported by the International Research Promotion Office of the Earthquake Research Institute and the European Research Council, grant no. 681346-REALISM. All datasets used in this paper have already been used by previous studies and are fully presented in the tables.

\section{References}

1. Abercrombie, R. E. \& Rice, J. R. 2005. Can observations of earthquake scaling constrain slip weakening? Geophysical Journal International 162(2), 406-424.

2. Abercrombie, R. E. 2019. Small and large earthquakes can have similar starts. Nature 573, 42-43.

3. Andersen, T.B. \& Austrheim, H. 2006. Fossil earthquakes recorded by pseudotachylytes in mantle peridotite from the Alpine subduction complex of Corsica. EPSL 242, 58-72.

4. Andersen, T., Austrheim, H., Deseta, N., Silkoset, P. \& Ashwal, L. 2014. Large subduction earthquakes along the fossil Moho in Alpine Corsica, Geology 42, 395-398.

This article is protected by copyright. All rights reserved. 
5. Aubry, J., Passelègue, F. X., Deldicque, D., Girault, F., Marty, S., Lahfid, A., ... \& Schubnel, A. 2018. Frictional heating processes and energy budget during laboratory earthquakes. Geophysical Research Letters 45(22), 12-274.

6. Barker, S. L. 2005. Pseudotachylyte-generating faults in central Otago, New Zealand. Tectonophysics 397(3-4), 211-223.

7. Beeler, N. M., Di Toro, G. \& Nielsen, S. 2016. Earthquake source properties from pseudotachylite. Bulletin of the Seismological Society of America 106(6), 2764-2776.

8. Beroza, G. C. \& Mikumo, T. 1996. Short slip duration in dynamic rupture in the presence of heterogeneous fault properties. Journal of Geophysical Research: Solid Earth 101(B10), 22449-22460.

9. Blundy, J., Cashman, K. \& Humphreys, M. 2006. Magma heating by decompression-driven crystallization beneath andesite volcanoes. Nature 443(7107), 76-80.

10. Bottinga, Y. \& Richet, P. 1995. Silicate melts: The "anomalous" pressure dependence of the viscosity. Geochimica et Cosmochimica Acta 59(13), 2725-2731.

11. Brantut, N. 2020. Dilatancy-induced fluid pressure drop during dynamic rupture: Direct experimental evidence and consequences for earthquake dynamics. Earth \& Planetary Science Letters 538, 116179.

12. Brantut, N., Passelègue, F. X., Deldicque, D., Rouzaud, J. N. \& Schubnel, A. 2016. Dynamic weakening and amorphization in serpentinite during laboratory earthquakes. Geology 44(8), 607-610.

13. Brantut, N., Schubnel, A., Rouzaud, J. N., Brunet, F. \& Shimamoto, T. 2008. High-velocity frictional properties of a clay-bearing fault gouge and implications for earthquake mechanics. Journal of Geophysical Research: Solid Earth 113(B10).

14. Brodsky, E. E. 2019. The importance of studying small earthquakes. Science 364(6442), 736-737.

15. Burbank, W. S. 1936. A source of heat-energy in crystallization of granodiorite magma, and some related problems of volcanism. Eos, Transactions American Geophysical Union 17(1), 236-255.

16. Camacho, A., Vernon, R. H. \& Gerald, J. F. 1995. Large volumes of anhydrous pseudotachylyte in the Woodroffe Thrust, eastern Musgrave Ranges, Australia. Journal of Structural Geology 17(3), 371-383.

17. Chattopadhyay, A., Khasdeo, L., Holdsworth, R. E. \& Smith, S. A. F. 2008. Fault reactivation and pseudotachylite generation in the semi-brittle and brittle regimes: examples from the Gavilgarh-Tan Shear Zone, central India. Geological Magazine 145(6), 766-777.

18. Costa, A. 2005. Viscosity of high crystal content melts: dependence on solid fraction. Geophysical Research Letters 32(22).

19. Del Gaudio, P., Di Toro, G., Han, R., Hirose, T., Nielsen, S., Shimamoto, T. \& Cavallo, A. 2009. Frictional melting of peridotite and seismic slip. Journal of Geophysical Research 114, B06306.

This article is protected by copyright. All rights reserved. 
20. Deseta, N., Ashwal, L. D. \& Andersen, T. B. 2014b. Initiating intermediate-depth earthquakes: Insights from a HP-LT ophiolite from Corsica. Lithos 206-207, 127-146.

21. Deseta, N., Andersen, T. B. \& Ashwal, L. D. 2014a. A weakening mechanism for intermediate-depth seismicity? Detailed petrographic and microtextural observations from blueschist facies pseudotachylytes, Cape Corse, Corsica. Tectonophysics 610, 138-149.

22. Di Toro, G., Goldsby, D. L. \& Tullis, T. E. 2004. Friction falls towards zero in quartz rock as slip velocity approaches seismic rates. Nature 427(6973), 436.

23. Di Toro, G., Pennacchioni, G. \& Teza, G. 2005. Can pseudotachylytes be used to infer earthquake source parameters? An example of limitations in the study of exhumed faults. Tectonophysics 402(14), 3-20.

24. Di Toro, G. \& Pennacchioni, G. 2005. Fault plane processes and mesoscopic structure of a strong-type seismogenic fault in tonalites (Adamello batholith, Southern Alps). Tectonophysics 402(1-4), 55-80.

25. Di Toro, G., Hirose, T., Nielsen, S., Pennacchioni, G. \& Shimamoto, T. 2006. Natural and experimental evidence of melt lubrication of faults during earthquakes, Science 311, 647-649.

26. Di Toro, G., Han, R., Hirose, T., De Paola, N., Nielsen, S., Mizoguchi, K., ... \& Shimamoto, T. 2011. Fault lubrication during earthquakes. Nature 471(7339), 494.

27. Dietz, R. S. 1961, Vredefort ring structure: meteorite impact scar? The Journal of Geology, 499-516.

28. Dingwell, D. B. \& Webb, S. L. 1989. Structural relaxation in silicate melts and non-Newtonian melt rheology in geologic processes. Physics \& Chemistry of Minerals 16(5), 508-516.

29. Dobson, D. P., Thomas, R. W. \& Mitchell, T. M. 2018. Diffusion profiles around quartz clasts as indicators of the thermal history of pseudotachylytes. Geochemistry, Geophysics, Geosystems 19(11), 4329-4341.

30. Fabbri, O., Lin, A. \& Tokushige, H. 2000. Coeval formation of cataclasite and pseudotachylyte in a Miocene forearc granodiorite, southern Kyushu, Japan. Journal of Structural Geology 22(8), 10151025.

31. Ferrand, T. P., Hilairet, N., Incel, S., Deldicque, D., Labrousse, L., Gasc, J., Renner, J., Wang, Y., Green, H. W. II \& Schubnel, A. 2017. Dehydration-driven stress transfer triggers intermediate-depth earthquakes. Nature Communications 8, 15247.

32. Ferrand, T. P. 2017. Reproduction expérimentale d'analogues de séismes mantelliques par déshydratation de l'antigorite et comparaison à des pseudotachylites naturelles. Laboratoire de Géologie de l'Ecole Normale Supérieure. PSL Research Unisversity.

This article is protected by copyright. All rights reserved. 
33. Ferrand, T. P., Labrousse, L., Eloy, G., Fabbri, O., Hilairet, N. \& Schubnel, A. 2018. Energy balance from a mantle pseudotachylyte, Balmuccia, Italy. Journal of Geophysical Research 123, 3943-3967.

34. Ferré, E. C., Geissman, J. W., Chauvet, A., Vauchez, A. \& Zechmeister, M. S. 2015. Focal mechanism of prehistoric earthquakes deduced from pseudotachylyte fabric. Geology 43(6), 531-534.

35. Gaetani, G. A. \& Grove, T. L. 1998. The influence of water on melting of mantle peridotite. Contributions to Mineralogy \& Petrology 131(4), 323-346.

36. Gupta, P. K. 1987. Negative pressure dependence of viscosity. Journal of the American Ceramic Society 70(7), C-152.

37. Griffith, W. A., Di Toro, G., Pennacchioni, G., Pollard, D. D. \& Nielsen, S. 2009. Static stress drop associated with brittle slip events on exhumed faults. Journal of Geophysical Research: Solid Earth 114(B2).

38. Griffith, W. A., Mitchell, T. M., Renner, J. \& Di Toro, G. 2012. Coseismic damage and softening of fault rocks at seismogenic depths. Earth \& Planetary Science Letters 353, 219-230.

39. Hayward, K. S., Hawkins, R., Cox, S. F. \& Le Losq, C. 2019. Rheological controls on asperity weakening during earthquake slip. Journal of Geophysical Research: Solid Earth 124(12), 12736-12762.

40. Hayward, K. S. \& Cox, S. F. 2017. Melt welding and its role in fault reactivation and localization of fracture damage in seismically active faults. Journal of Geophysical Research: Solid Earth 122(12), 9689-9713.

41. Hayward, K. S., Cox, S. F., Gerald, J. D. F., Slagmolen, B. J., Shaddock, D. A., Forsyth, P. W., ... \& Hawkins, R. P. 2016. Mechanical amorphization, flash heating, and frictional melting: Dramatic changes to fault surfaces during the first millisecond of earthquake slip. Geology 44(12), 1043-1046.

42. Heaton, T. H. 1990. Evidence for and implications of self-healing pulses of slip in earthquake rupture, Physics of the Earth \& Planetary Interiors 64 (1), 1-20.

43. Hirose, T. \& Shimamoto, T. 2005a. Growth of molten zone as a mechanism of slip weakening of simulated faults in gabbro during frictional melting, Journal of Geophysical Research: Solid Earth 110 (B5).

44. Hirose, T. \& Shimamoto, T. 2005b. Slip-Weakening Distance of Faults during Frictional Melting as Inferred from Experimental and Natural Pseudotachylytes. Bulletin of the Seismological Society of America 95, 5, 1666-1673.

45. Holtz, F., Roux, J., Ohlhorst, S., Behrens, H. \& Schulze, F. 1999. The effects of silica and water on the viscosity of hydrous quartzofeldspathic melts. American Mineralogist 84(1-2), 27-36.

This article is protected by copyright. All rights reserved. 
46. Ide, S. 2019. Frequent observations of identical onsets of large and small earthquakes. Nature, 573(7772), 112-116.

47. Incel, S., Hilairet, N., Labrousse, L., John, T., Deldicque, D., Ferrand, T., Wang, Y., Renner, J., Morales, L. \& Schubnel, A. 2017. Laboratory earthquakes triggered during eclogitization of lawsonite bearing blueschist, Earth \& Planetary Science Letters 459, 320-331.

48. Johnson, K. M., Hsu, Y. J., Segall, P. \& Yu, S. B. 2001. Fault geometry and slip distribution of the 1999 Chi-Chi, Taiwan earthquake imaged from inversion of GPS data. Geophysical Research Letters 28(11), 2285-2288.

49. Kanamori, H. 1977. The Energy Release in Great Earthquakes, Journal of Geophysical Research 82, 2981-2987.

50. Kanamori, H., Anderson, D. L. \& Heaton, T. H. 1998. Frictional melting during the rupture of the 1994 Bolivian earthquake. Science 279(5352), 839-842.

51. Karki, B. B., Zhang, J. \& Stixrude, L. 2013. First principles viscosity and derived models for $\mathrm{MgO}^{-\mathrm{SiO}_{2}}$ melt system at high temperature. Geophysical Research Letters 40(1), 94-99.

52. Kilb, D. \& Gomberg, J. 1999. The initial subevent of the 1994 Northridge, California, earthquake: Is earthquake size predictable? Journal of Seismology 3(4), 409-420.

53. Kim, J. W., Ree, J. H., Han, R. \& Shimamoto, T. 2010. Experimental evidence for the simultaneous formation of pseudotachylyte and mylonite in the brittle regime. Geology 38(12), 1143-1146.

54. Kita, S. \& Ferrand, T. P. 2018. Physical mechanisms of oceanic mantle earthquakes: Comparison of natural and experimental events. Scientific reports 8(1), 17049.

55. Kirkpatrick, J. D. \& Rowe, C. D. 2013. Disappearing ink: How pseudotachylytes are lost from the rock record. Journal of Structural Geology 52, 183-198.

56. Kirkpatrick, J. D. \& Shipton, Z. K. 2009. Geologic evidence for multiple slip weakening mechanisms during seismic slip in crystalline rock. Journal of Geophysical Research: Solid Earth 114(B12).

57. Kirkpatrick, J. D., Shipton, Z. K. \& Persano, C. 2009. Pseudotachylytes: Rarely generated, rarely preserved, or rarely reported? Bulletin of the Seismological Society of America 99(1), 382-388.

58. Kushiro, I., Yoder Jr, H. S. \& Mysen, B. O. 1976. Viscosities of basalt and andesite melts at high pressures. Journal of geophysical research 81(35), 6351-6356.

59. Le Losq, C., R. Moretti \& D. R. Neuville 2013. Speciation and amphoteric behaviour of water in aluminosilicate melts and glasses: high-temperature Raman spectroscopy and reaction equilibria, European Journal of Mineralogy, 25 (5), 777-790.

This article is protected by copyright. All rights reserved. 
60. Liebske, C., Schmickler, B., Terasaki, H., Poe, B. T., Suzuki, A., Funakoshi, K. I., ... \& Rubie, D. C. 2005. Viscosity of peridotite liquid up to $13 \mathrm{GPa}$ : Implications for magma ocean viscosities. Earth \& Planetary Science Letters 240(3-4), 589-604.

61. Lin, A. 1994. Glassy pseudotachylyte veins from the Fuyun fault zone, northwest China. Journal of Structural Geology 16(1), 71-83.

62. Lockner, D. A., Kilgore, B. D., Beeler, N. M. \& Moore, D. E. 2017. The transition from frictional sliding to shear melting in laboratory stick-slip experiments. Fault zone dynamic processes: Evolution of fault properties during seismic rupture 227, 105.

63. Marti, S., Stünitz, H., Heilbronner, R. \& Plümper, O. 2020. Amorphous material in experimentally deformed mafic rock and its temperature dependence: Implications for fault rheology during aseismic creep and seismic rupture. Journal of Structural Geology 104081.

64. Marty, S., Passelègue, F. X., Aubry, J., Bhat, H. S., Schubnel, A. \& Madariaga, R. 2019. On the origin of high-frequency radiation in experimental earthquakes. arXiv preprint arXiv:1901.01219.

65. Masch, L., Wenk, H. R. \& Preuss, E. 1985. Electron microscopy study of hyalomylonites-evidence for frictional melting in landslides. Tectonophysics 115(1-2), 131-160.

66. McKenzie, D. \& Brune, J. N. 1972. Melting on fault planes during large earthquakes. Geophysical Journal International, 29(1), 65-78.

67. Mei, S. \& Kohlstedt, D. L. 2000. Influence of water on plastic deformation of olivine aggregates: 1. Diffusion creep regime. Journal of Geophysical Research: Solid Earth 105(B9), 21457-21469.

68. Mei, S. \& Kohlstedt, D. L. 2000. Influence of water on plastic deformation of olivine aggregates: 2. Dislocation creep regime, Journal of Geophysical Research: Solid Earth 105(B9), 21471-21481.

69. Mitchell, T. M., Toy, V., Di Toro, G., Renner, J. \& Sibson, R. H. 2016. Fault welding by pseudotachylyte formation. Geology 44(12), 1059-1062.

70. Nielsen, S., Di Toro, G., Hirose, T. \& Shimamoto, T. 2008. Frictional melt and seismic slip. Journal of Geophysical Research: Solid Earth 113(B1): B01308.

71. Nielsen, S., Di Toro, G. \& Griffith, W. A. 2010a. Friction and roughness of a melting rock surface. Geophysical Journal International 182(1), 299-310.

72. Nielsen, S., Mosca, P., Giberti, G., Di Toro, G., Hirose, T. \& Shimamoto, T. 2010b. On the transient behavior of frictional melt during seismic slip. Journal of Geophysical Research: Solid Earth 115(B10).

73. Nielsen, S., Spagnuolo, E., Smith, S., Violay, M., Di Toro, G. \& Bistacchi, A. 2016. Scaling in natural and laboratory earthquakes, Geophysical Research Letters.

This article is protected by copyright. All rights reserved. 
74. Niemeijer, A., Di Toro, G., Nielsen, S. \& Di Felice, F. 2011. Frictional melting of gabbro under extreme experimental conditions of normal stress, acceleration, and sliding velocity. Journal of Geophysical Research: Solid Earth 116(B7).

75. Obata, M. \& Karato, S. 1995. Ultramafic pseudotachylite from the Balmuccia peridotite, IvreaVerbano zone, northern Italy. Tectonophysics 242, 313-328.

76. Ohnaka, M. 2003. A constitutive scaling law and a unified comprehension for frictional slip failure, shear fracture of intact rock, and earthquake rupture. Journal of Geophysical Research: Solid Earth 108(B2).

77. Okubo, K., Bhat, H. S., Rougier, E., Marty, S., Schubnel, A., Lei, Z., ... \& Klinger, Y. 2019. Dynamics, radiation and overall energy budget of earthquake rupture with coseismic off-fault damage. arXiv preprint arXiv:1901.01771.

78. Otsuki, K., Monzawa, N. \& Nagase, T. 2003. Fluidization and melting of fault gouge during seismic slip: Identification in the Nojima fault zone and implications for focal earthquake mechanisms. Journal of Geophysical Research: Solid Earth 108(B4).

79. Passelègue, F. X. 2014. Etude expérimentale de la rupture sismique (Doctoral dissertation, Paris, Ecole normale supérieure).

80. Passelègue, F., Schubnel, A., Nielsen, S., Bhat, H. S., Deldicque, D. \& Madariaga, R. 2016a. Dynamic rupture processes inferred from laboratory microearthquakes. Journal of Geophysical Research: Solid Earth 121(6), 4343-4365.

81. Passelègue, F., Spagnuolo, E., Violay, M., Nielsen, S., Di Toro, G. \& Schubnel, A. 2016b. Frictional evolution, acoustic emissions activity, and off-fault damage in simulated faults sheared at seismic slip rates. Journal of Geophysical Research: Solid Earth 121(10), 7490-7513.

82. Phillips, N. J., Rowe, C. D. \& Ujiie, K. 2019. For how long are pseudotachylytes strong? Rapid alteration of basalt-hosted pseudotachylytes from a shallow subduction complex. Earth \& Planetary Science Letters 518, 108-115.

83. Philpotts, A. R. 1964. Origin of pseudotachylytes. American Journal of Science, 262, 1008-1035.

84. Proctor, B. \& Lockner, D. A. 2016. Pseudotachylyte increases the post-slip strength of faults. Geology 44(12), 1003-1006.

85. Pittarello, L., Pennacchioni, G. \& Di Toro, G. 2012. Amphibolite-facies pseudotachylytes in Premosello metagabbro and felsic mylonites (Ivrea Zone, Italy). Tectonophysics 580, 43-57.

This article is protected by copyright. All rights reserved. 
86. Pittarello, L., Di Toro, G., Bizzarri, A., Pennacchioni, G., Hadizadeh, J. \& Cocco, M. 2008. Energy partitioning during seismic slip in pseudotachylyte-bearing faults (Gole Larghe Fault, Adamello, Italy). Earth \& Planetary Science Letters 269(1-2), 131-139.

87. Romanet, P., Bhat, H. S., Jolivet, R. \& Madariaga, R. 2018. Fast and slow slip events emerge due to fault geometrical complexity. Geophysical Research Letters.

88. Petley-Ragan, A., Ben-Zion, Y., Austrheim, H., Ildefonse, B., Renard, F. \& Jamtveit, B. 2019. Dynamic earthquake rupture in the lower crust. Science advances 5(7), eaaw0913.

89. Petley-Ragan, A., Dunkel, K. G., Austrheim, H., Ildefonse, B. \& Jamtveit, B. 2018. Microstructural records of earthquakes in the lower crust and associated fluid-driven metamorphism in plagioclaserich granulites. Journal of Geophysical Research: Solid Earth 123(5), 3729-3746.

90. Rempel, A. W. \& Rice, J. R. 2006. Thermal pressurization and onset of melting in fault zones. Journal of Geophysical Research: Solid Earth 111(B9).

91. Rice, J. R. 2006. Heating and weakening of faults during earthquake slip. Journal of Geophysical Research: Solid Earth 111(B5).

92. Richet, P., Lejeune, A. M., Holtz, F. \& Roux, J. 1996. Water and the viscosity of andesite melts. Chemical Geology 128(1-4), 185-197.

93. Scambelluri, M., Pennacchioni, G., Gilio, M., Bestmann, M., Plümper, O. \& Nestola, F. 2017. Fossil intermediate-depth earthquakes in subducting slabs linked to differential stress release. Nature Geoscience 10(12), 960.

94. Schubnel, A., Brunet, F., Hilairet, N., Gasc, J., Wangand, Y. \& Green, H. W. II. 2013. Deep-Focus Earthquake Analogs Recorded at High Pressure and Temperature in the Laboratory, Science 341, 1377-1380.

95. Shand, S. J. 1916. The pseudotachylyte of Parijs (Orange free State), and its relation to 'Trap-Shotten Gneiss' and 'Flinty Crush-rock'. Quarterly Journal of the Geological Society 72(1-4), 198-221.

96. Sibson, R. H. 1975. Generation of pseudotachylyte by ancient seismic faulting. Geoph. Geophysical Journal of the Royal Astronomical Society 43, 775-794.

97. Sibson, R. H. 1980. Transient discontinuities in ductile shear zones. Journal of Structural Geology 2(12), 165-171.

98. Sibson, R. H. 1987. Earthquake rupturing as a mineralizing agent in hydrothermal systems. Geology 15(8), 701-704.

99. Sibson, R. H. \& Toy, V. G. 2006. The habitat of fault-generated pseudotachylyte: Presence vs. absence of friction-melt. Geophysical Monograph - AGU, 170, 153.

This article is protected by copyright. All rights reserved. 
100. Spray, J.G. 1987. Artificial generation of psuedotachylyte using friction welding apparatus: Simulation of melting on a fault plane. Journal of Structural Geology 9, 49-60.

101. Spray, J. G. 1993. Viscosity determinations of some frictionally generated silicate melts: Implications for fault zone rheology at high strain rates. Journal of Geophysical Research: Solid Earth 98(B5), 80538068.

102. Spray, J. G. 2010. Frictional melting processes in planetary materials: From hypervelocity impact to earthquakes. Annual Review of Earth \& Planetary Sciences 38, 221-254.

103. Suzuki, A., Ohtani, E., Urakawa, S., Terasaki, H. \& Kato, T. 2001. Viscosity of komatiite magma at high pressure, in Bayerisches Forschungs institut für Experimentelle Geochemie und Geophysik, Universität Bayreuth Annual Report, p. 105, Princeton University Press.

104. Suzuki, A., Ohtani, E., Funakoshi, K., Terasaki, H. \& Kubo, T. 2002. Viscosity of albite melt at high pressure and high temperature. Physics \& Chemistry of Minerals 29(3), 159-165.

105. Taniguchi, H. 1992. Entropy dependence of viscosity and the glass-transition temperature of melts in the system diopside-anorthite. Contributions to Mineralogy \& Petrology 109, 295-303.

106. Tinker, D., Lesher, C. E., Baxter, G. M., Uchida, T. \& Wang, Y. 2004. High-pressure viscometry of polymerized silicate melts and limitations of the Eyring equation. American Mineralogist 89(11-12), 1701-1708.

107. Thomas, M. Y., Bhat, H. S. \& Klinger, Y. 2017. Effect of brittle off-fault damage on earthquake rupture dynamics. Fault zone dynamic processes: Evolution of fault properties during seismic rupture, 227, 255.

108. Toplis, M. J., \& Dingwell, D. B. 2004. Shear viscosities of $\mathrm{CaO}-\mathrm{Al}_{2} \mathrm{O}_{3}-\mathrm{SiO}_{2}$ and $\mathrm{MgO}-\mathrm{Al}_{2} \mathrm{O}_{3}-\mathrm{SiO}_{2}$ liquids: Implications for the structural role of aluminium and the degree of polymerisation of synthetic and natural aluminosilicate melts. Geochimica et Cosmochimica Acta 68(24), 5169-5188.

109. Toyoshima, T. 1990. Pseudotachylite from the Main Zone of the Hidaka metamorphic belt, Hokkaido, northern Japan. Journal of Metamorphic Geology 8(5), 507-523.

110. Uchida, N. \& Bürgmann, R. 2019. Repeating earthquakes. Annual Review of Earth \& Planetary Sciences 47, 305-332.

111. Ueda, T., Obata, M., Di Toro, G., Kanagawa, K. \& Ozawa, K. 2008. Mantle earthquakes frozen in mylonitized ultramafic pseudotachylytes of spinel-Iherzolite facies. Geology 36, 607-610.

112. Vetere, F., Behrens, H., Holtz, F. \& Neuville, D. R. 2006. Viscosity of andesitic melts - new experimental data and a revised calculation model. Chemical Geology 228, 233-245.

113. Viesca, R. C. \& Garagash, D. I. 2015. Ubiquitous weakening of faults due to thermal pressurization. Nature Geoscience 8(11), 875.

This article is protected by copyright. All rights reserved. 
114. Violay, M., Nielsen, S., Gibert, B., Spagnuolo, E., Cavallo, A., Azais, P., ... \& Di Toro, G. 2014. Effect of water on the frictional behavior of cohesive rocks during earthquakes. Geology 42(1), 27-30.

115. Violay, M., Di Toro, G., Nielsen, S., Spagnuolo, E. \& Burg, J. P. 2015. Thermo-mechanical pressurization of experimental faults in cohesive rocks during seismic slip. Earth \& Planetary Science Letters 429, 110.

116. Warr, L. N. \& van der Pluijm, B. A. 2005. Crystal fractionation in the friction melts of seismic faults (Alpine Fault, New Zealand). Tectonophysics 402(1-4), 111-124.

117. Webb, S. L. \& Dingwell, D. B. 1990. Non-Newtonian rheology of igneous melts at high stresses and strain rates: Experimental results for rhyolite, andesite, basalt, and nephelinite. Journal of Geophysical Research: Solid Earth 95(B10), 15695-15701.

118. Whittington, A., Richet, P. \& Holtz, F. 2000. Water and the viscosity of depolymerized aluminosilicate melts. Geochimica et Cosmochimica Acta 64(21), 3725-3736.

119. Wilshire, H. 1971, Pseudotachylite from the Vredefort Ring, South Africa, The Journal of Geology. 195206.

120. Wyss, M. 2001. Why is earthquake prediction research not progressing faster? Tectonophysics 338(34), 217-223.

121. Xue, X., Stebbins, J. F., Kanzaki, M., McMillan, P. F. \& Poe, B. 1991. Pressure-induced silicon coordination and tetrahedral structural changes in alkali oxide-silica melts up to $12 \mathrm{GPa}$ : NMR, Raman, and infrared spectroscopy. American Mineralogist 76(1-2), 8-26.

This article is protected by copyright. All rights reserved. 


\section{Figures}

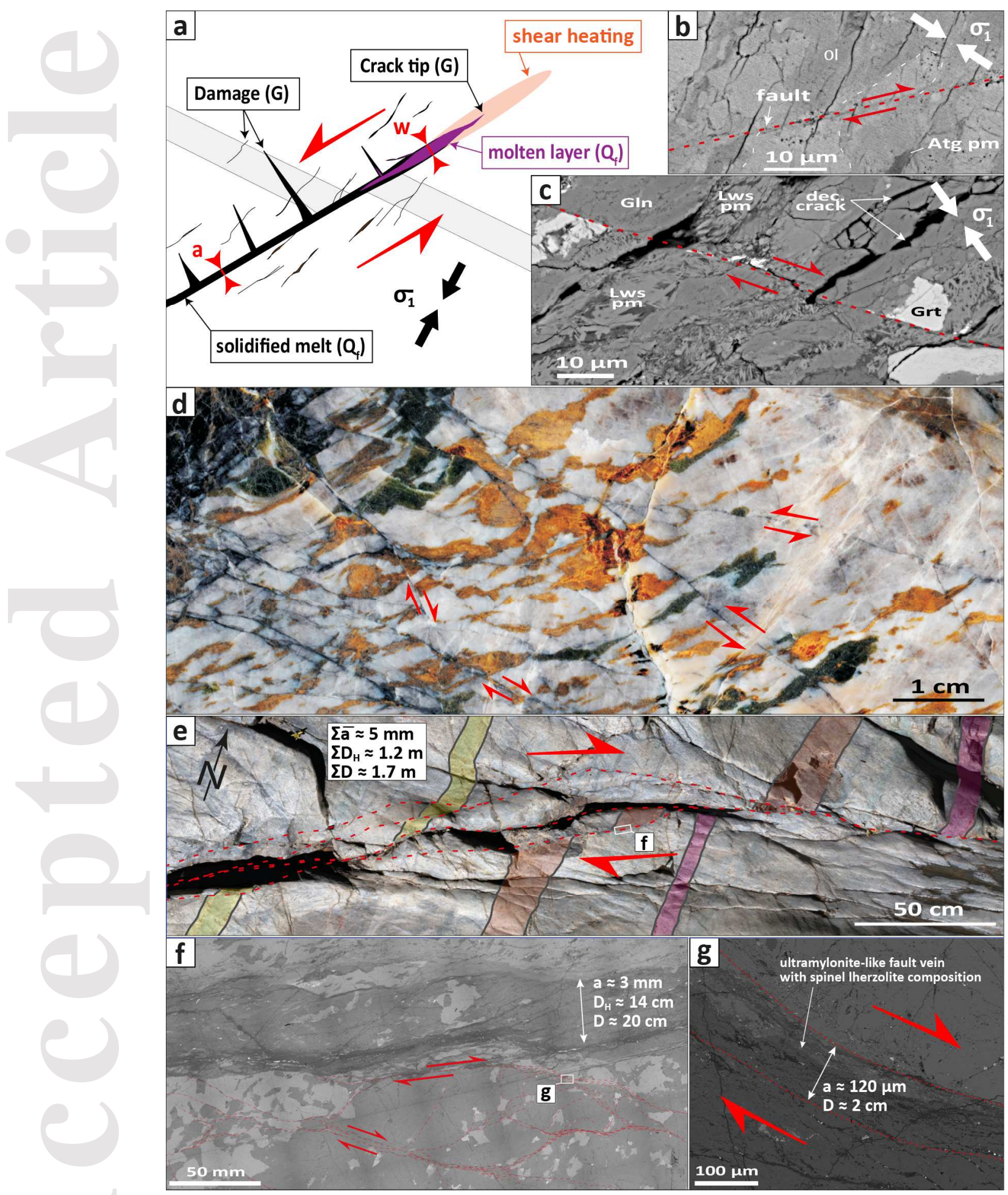

Figure 1: Laboratory and field observations of pseudotachylytes. a: Sketch of pseudotachylyte formation within a rock containing a displacement marker (energy partitioning between heat $Q$ and fracture energy 
$G$; distinction between final thickness $a$ and dynamic melt width $w$. Arrows show the maximum compression direction ( $\sigma_{1}$; black) and the sense of shear (red). b: Experimental pseudotachylyte in olivine due to antigorite dehydration ( $D=10 \mu \mathrm{m} ; a=20-200 \mathrm{~nm}$; Ferrand et al., 2017). White dots define an intensely sheared olivine grain. c: Experimental pseudotachylyte in a blueschist due to lawsonite dehydration ( $D=36 \mu \mathrm{m} ; a=10-50 \mathrm{~nm}$ ). The displacement marker is a garnet grain (Grt). Lawsonite pseudomorphs (Lws pm) consist of epidote needles and omphacite. Gln = glaucophane; dec. = decompression. d: Oceanic mylonitic gabbro (Scambelluri et al., 2017) made of green clinopyroxene (green), olivine (orange) and plagioclase (white). Black thin lines are the network of pseudotachylyte fault veins cutting the mylonitic foliation ( $D=1 \mathrm{~cm}$ for $a=100 \mu \mathrm{m} ; D=500 \mu \mathrm{m}$ for $a=20 \mathrm{~nm}$ ). e: Natural high-pressure fault found in the Balmuccia peridotite (subvertical; $D=1.7 \pm 0.2 \mathrm{~m} ; a=5 \mathrm{~mm} ; w<2 \mathrm{~cm}$ Ferrand et al., 2018). $\mathbf{f : ~ C l o s e r ~ v i e w ~ o f ~ ( e ) ~ s h o w i n g ~ o n e ~ o f ~ t h e ~ m a i n ~ f a u l t ~ v e i n s ~ ( ~} D=20 \mathrm{~cm} ; a=3 \mathrm{~mm})$. $\mathbf{g}$ : Network of ultramylonite-like veins highlighted in (f) $(D=2 \mathrm{~cm} ; a=120 \mu \mathrm{m})$. See the associated Table 1 for details and additional references.

This article is protected by copyright. All rights reserved. 


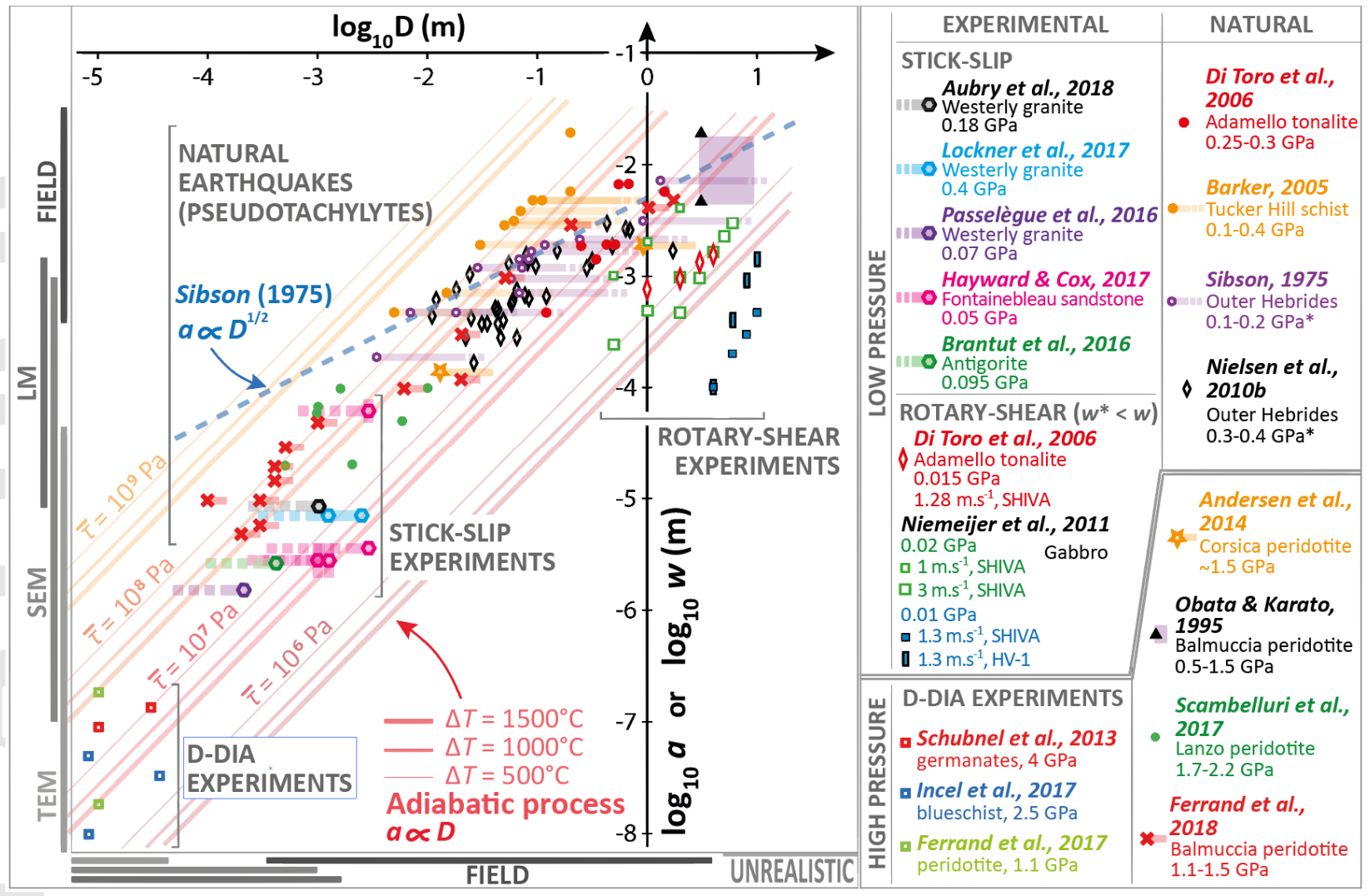

Figure 2: Displacement as a function of fault thickness: datasets and adiabatic assumption. Observations

from field work (1 mm - $10 \mathrm{~m})$ and various microscopy techniques (10 nm - $1 \mathrm{~mm})$. Dataset come from a review of published studies (Table 1). Field-scale data are compared to micrometer-scale and nanometerscale observations. A distinction is made between the pseudotachylyte thickness $a$ (fossilized trace of the seismic rupture, i.e. observational data) and the dynamic thickness $w$ (volume of melt produced by surface unit, i.e. simple adiabatic model). Values of $a$ and $w$ should slightly differ considering off fault damage and melt intrusion (section 2.2). All the faults are reported as pseudotachylyte, except the ones of Schubnel et al. (2013; "transformational faulting" during olivine-spinel transition). Data from Scambelluri et al. (2017) are from the fault network shown in Fig. 1. The datasets of Barker (2005) and Sibson (1975) are minimum estimates of $D$, which could be one or two orders of magnitude larger (see discussion in section 2.1). Rotary-shear experiments provide two distinct datasets: sample axial shortening $w^{*}$ (cumulative melt thickness) and the final pseudotachylyte thickness $a^{*}$ (Hirose \& Shimamoto, 2005; Del Gaudio et al., 2009)

This article is protected by copyright. All rights reserved. 
that is not considered here (section 2.1). Gray sidebars recall the limits of Light Microscopy (LM) and Scanning (SEM) and Transmission Electron Microscopy (TEM). Calculations provided in section 2.2. The density is considered to be equal to $2900 \mathrm{~kg} \cdot \mathrm{m}^{-3}$, and its variability does not have much influence on the results). Uncertainties about the dynamic temperature rise $\Delta T$ are considered. The range of average shear stress $\bar{\tau}$ is consistent with typical seismological estimates. See Table 1 for information about the datasets.

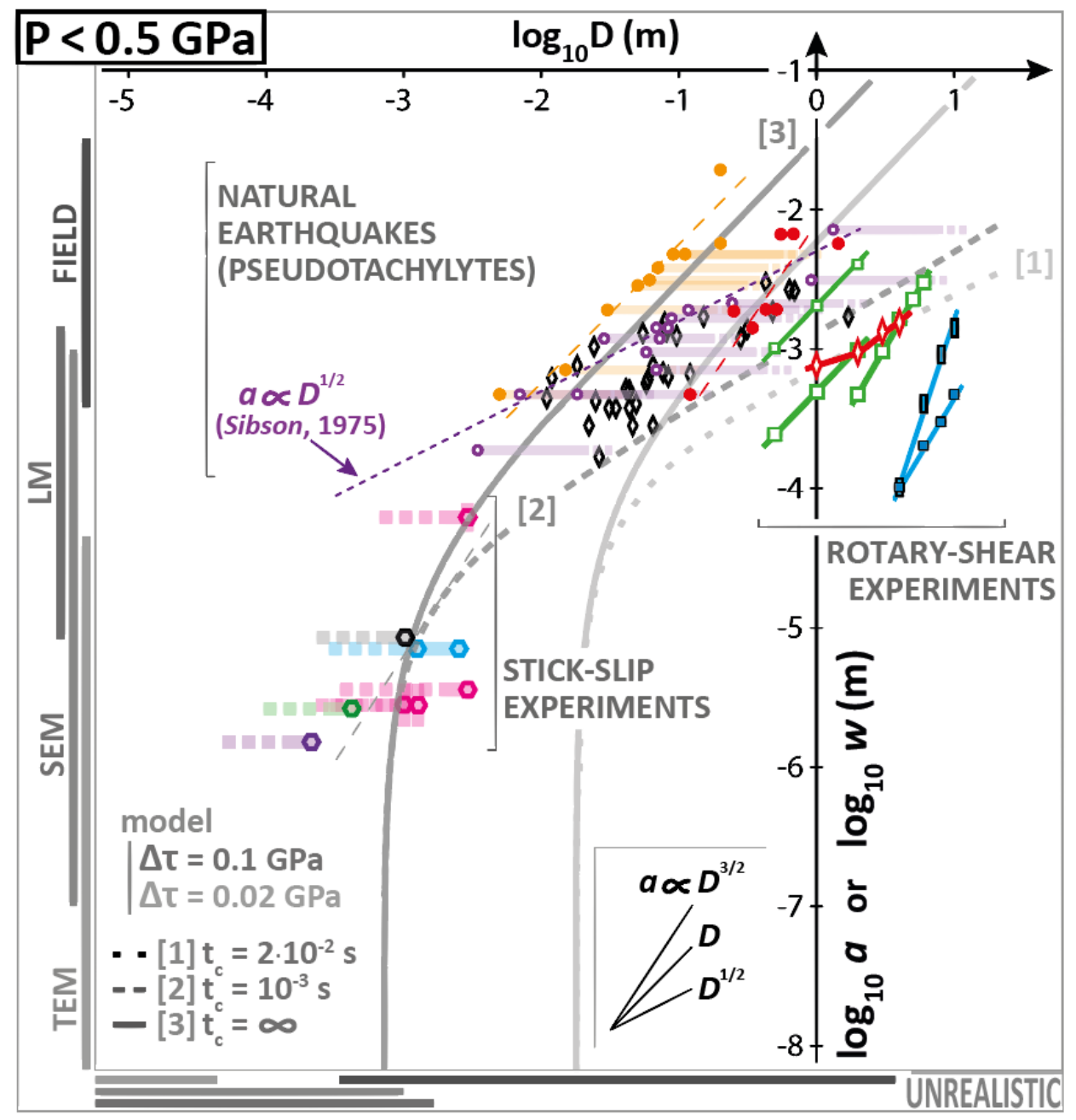

Figure 3: Scaling seismic fault thickness with displacement as a Stefan problem (low pressures). Gray curves show the results of the model (see section 3 ) considering a peridotite and a constant sliding velocity $V=1 \mathrm{~m} \cdot \mathrm{s}^{-1}$ for [1] the onset of weakening $\left(t_{c}=2 \cdot 10^{-2} \mathrm{~s}\right),[2] t_{c}=10^{-3} \mathrm{~s}$ and [3] $t_{c}=\infty$ (constant power). The calculation is made for values of $\Delta \tau$ relevant for the pressure conditions. The dataset is presented in Fig.2, Table 1 and Table2.

This article is protected by copyright. All rights reserved. 


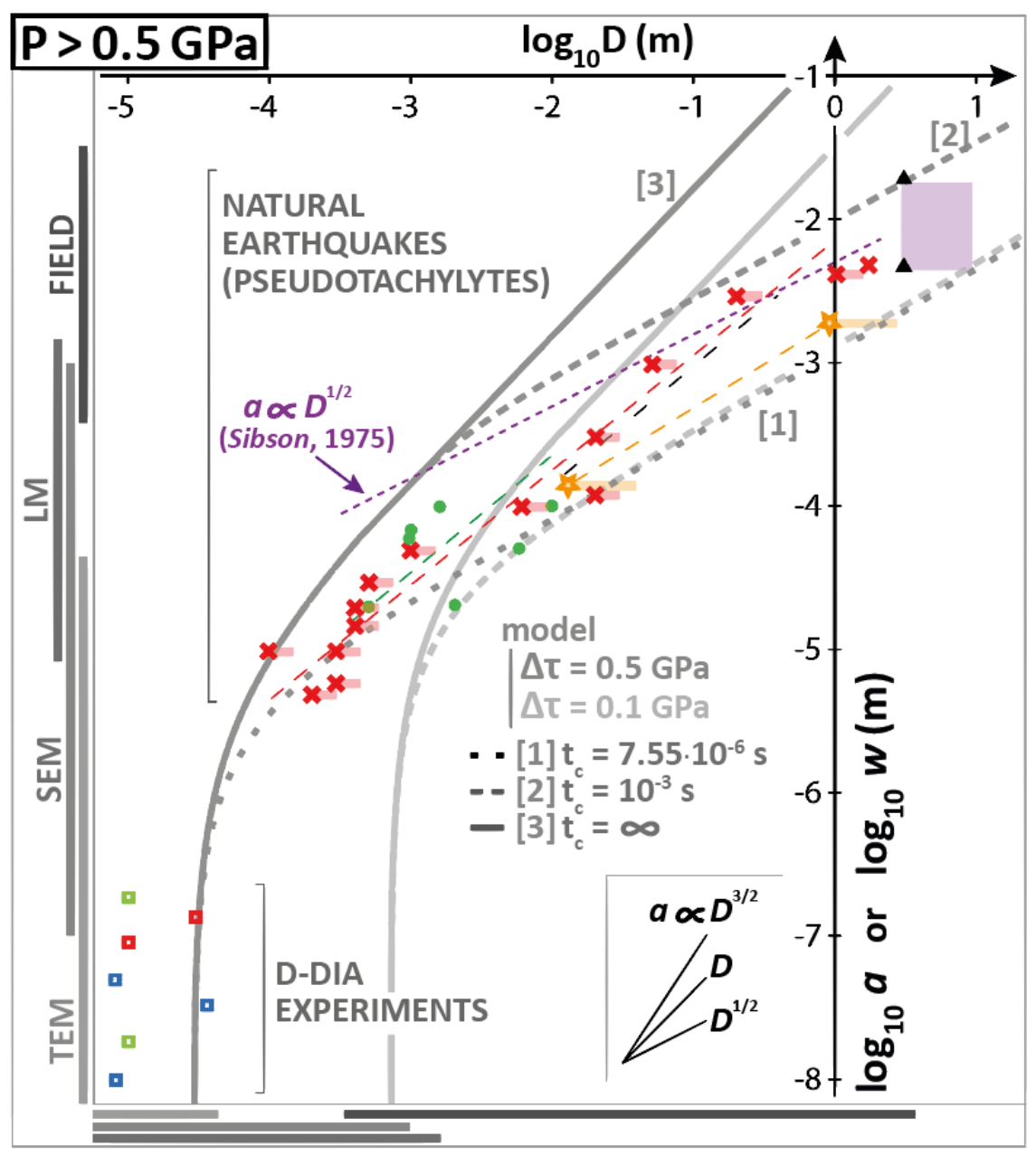

Figure 4: Scaling seismic fault thickness with displacement as a Stefan problem (high pressures). Gray curves show the results of the model (see section 3 ) considering a peridotite and a constant sliding velocity $V=1 \mathrm{~m} \cdot \mathrm{s}^{-1}$ for [1] the onset of weakening $\left(t_{c}=7.55 \cdot 10^{-6} \mathrm{~s}\right),[2] t_{c}=10^{-3} \mathrm{~s}$ and [3] $t_{c}=\infty$ (constant power). The calculation is made for values of $\Delta \tau$ relevant for the pressure conditions. The dataset is presented in Fig.2 and Table 1.

This article is protected by copyright. All rights reserved. 


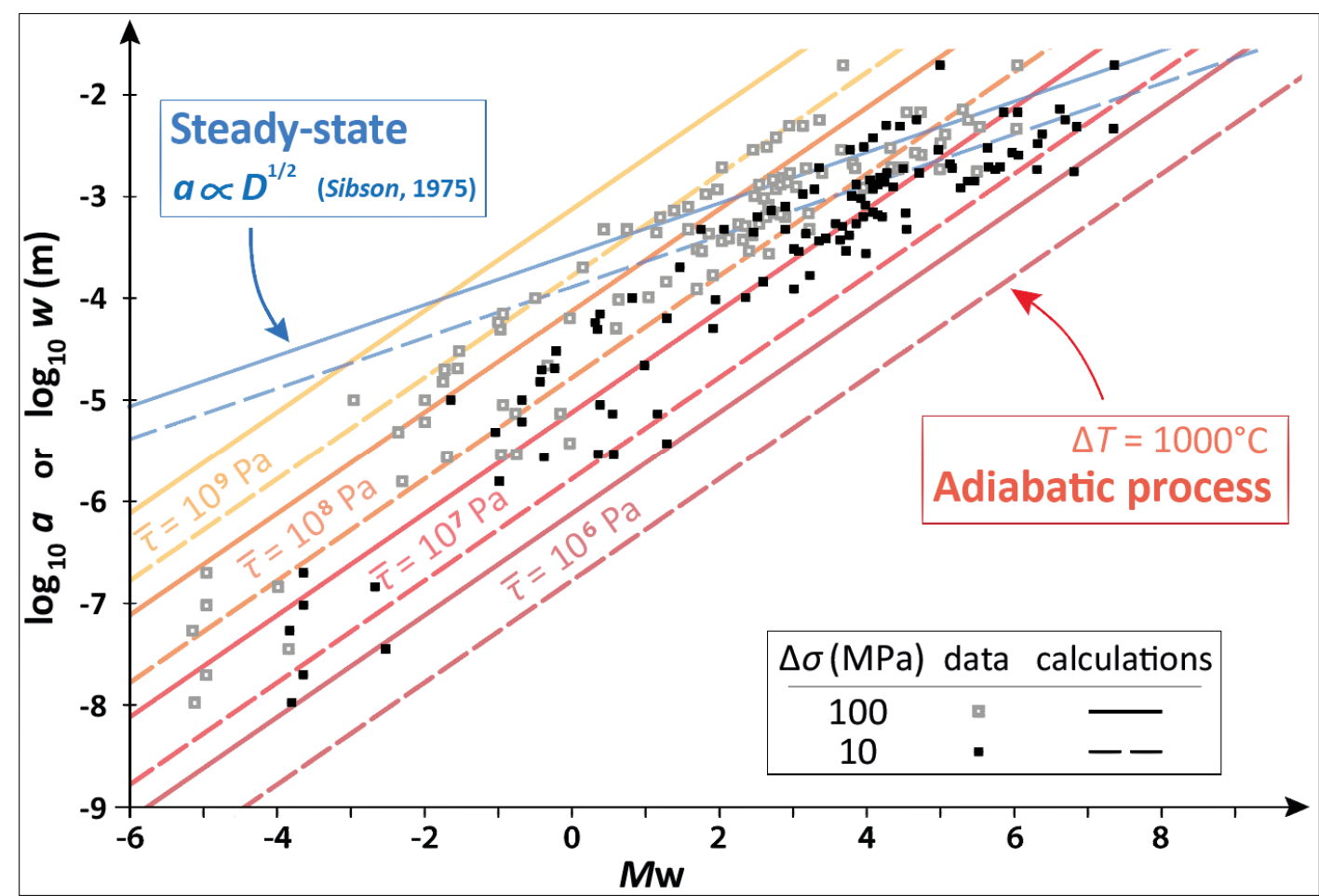

Figure 5: Fault thickness and direct magnitude estimates. a: pseudotachylyte thickness $a$ (data) and dynamic molten zone width $w$ (calculations) vs. earthquake magnitude $M \mathrm{w}$, with $M \mathrm{w}=$ $2 / 3 \log _{10} M_{0}-6.07$ (section 4.3) and $M_{0}$ from eq. (12). Warm colors correspond to the adiabatic process (eq. 15) whereas the blue color is used for the diabatic process (Sibson's law), which actually corresponds to the steady-state value of the Stefan problem described in this study (eq. 16).

This article is protected by copyright. All rights reserved. 


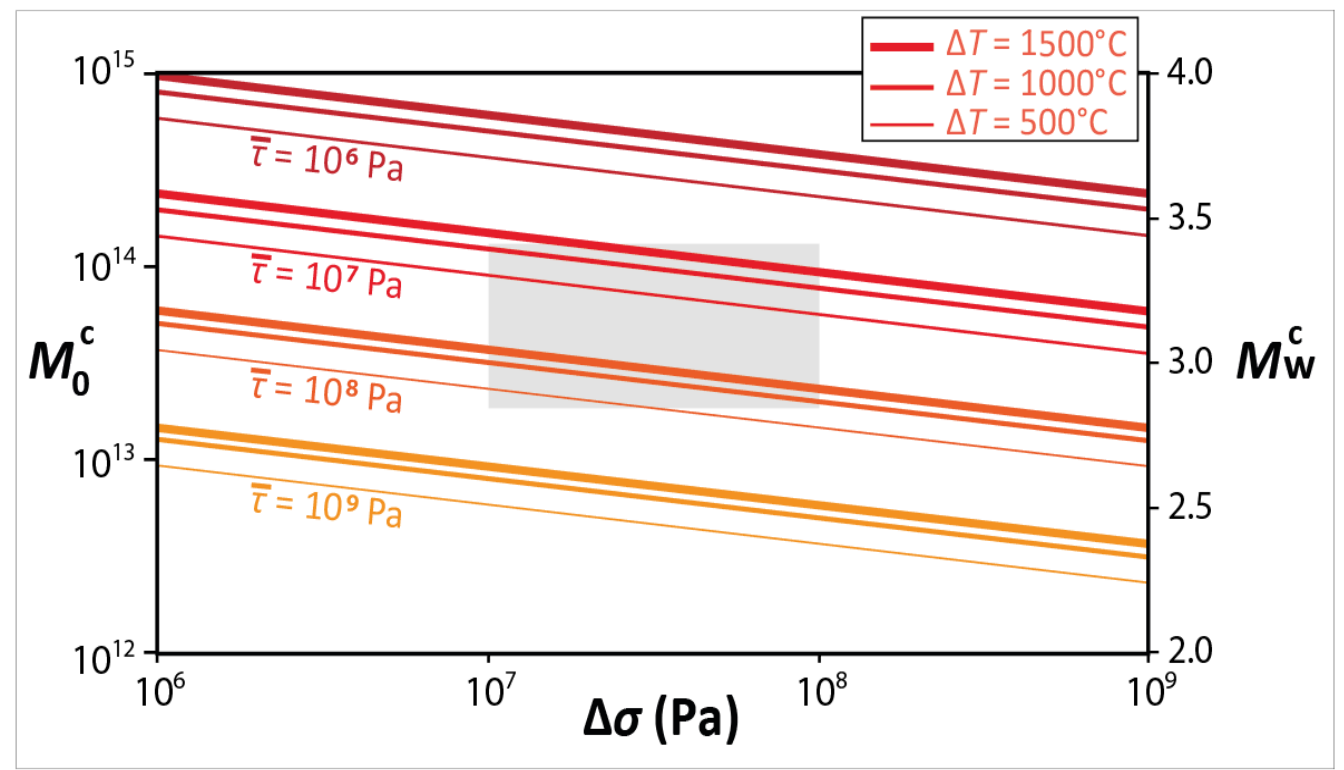

Figure 6: Crossover moment $M_{0}{ }^{c}$ and moment magnitude $M w^{c}$.

$M_{0}{ }^{c o}$ as function of $\bar{\tau}$ and $\Delta \sigma$ showing limited influence of $\Delta T$. The gray box indicates the range of values consistent with observation, as discussed in section $\mathbf{3 . 3}$ of the main manuscript.

This article is protected by copyright. All rights reserved. 


\section{Tables}

Table 1 - Dataset collected from various experimental and field works and presented in Fig. 2.

\begin{tabular}{|c|c|c|c|}
\hline$a$ & $\boldsymbol{D}$ & Material & Reference \\
\hline \multicolumn{4}{|c|}{ D-DIA experiments } \\
\hline $200 \mathrm{~nm}$ & $10 \mu \mathrm{m}$ & \multirow{2}{*}{ Olivine-antigorite aggregates } & \multirow{2}{*}{ Ferrand et al. (2017) } \\
\hline $20 \mathrm{~nm}$ & $10 \mu \mathrm{m}$ & & \\
\hline $10 \mathrm{~nm}$ & $8 \mu \mathrm{m}$ & \multirow{3}{*}{ Lawsonite blueschist } & \multirow{3}{*}{ Incel et al. (2017) } \\
\hline $50 \mathrm{~nm}$ & $8 \mu \mathrm{m}$ & & \\
\hline $30 \mathrm{~nm}$ & $6 \mu \mathrm{m}$ & & \\
\hline $100 \mathrm{~nm}$ & $10 \mu \mathrm{m}$ & \multirow{2}{*}{ Ge-olivine } & \multirow{2}{*}{ Schubnel et al. (2013) } \\
\hline $150 \mathrm{~nm}$ & $30 \mu \mathrm{m}$ & & \\
\hline \multicolumn{4}{|c|}{ Stick-slip experiments } \\
\hline $1.5 \mu \mathrm{m}$ & $250 \mu \mathrm{m}$ & \multirow{4}{*}{ Westerly granite } & Passelègue et al. (2016a) \\
\hline $8 \mu \mathrm{m}$ & $1.2 \mathrm{~mm}$ & & Aubry et al. (2018, supp. Mat.) \\
\hline $7 \mu \mathrm{m}$ & $1.2 \mathrm{~mm}$ & & \multirow{2}{*}{ Lockner et al. (2017) } \\
\hline $7 \mu \mathrm{m}$ & $4.2 \mathrm{~mm}$ & & \\
\hline $2.5 \mu \mathrm{m}$ & $500 \mu \mathrm{m}$ & Alpine Corsica antigorite & Brantut et al. (2016) \\
\hline $2-4 \mu \mathrm{m}$ & $1.35 \mathrm{~mm}$ & \multirow{4}{*}{$\begin{array}{l}\text { Fontainebleau sandstone, } \\
\quad>99 \% \text { quartz }\end{array}$} & \multirow{4}{*}{ Hayward \& Cox (2017) } \\
\hline $2-4 \mu \mathrm{m}$ & $1.09 \mathrm{~mm}$ & & \\
\hline $3-4 \mu \mathrm{m}$ & $2.28 \mathrm{~mm}$ & & \\
\hline $50-80 \mu \mathrm{m}$ & $2.28 \mathrm{~mm}$ & & \\
\hline \multicolumn{4}{|c|}{ Field work } \\
\hline $50 \mu \mathrm{m}$ & $6 \mathrm{~mm}$ & \multirow{7}{*}{$\begin{array}{l}\text { Lanzo peridotite, } \\
\text { Italian Alps }\end{array}$} & \multirow{7}{*}{ Scambelluri et al. (2017) } \\
\hline $20 \mu \mathrm{m}$ & $2 \mathrm{~mm}$ & & \\
\hline $70 \mu \mathrm{m}$ & $1 \mathrm{~mm}$ & & \\
\hline $100 \mu \mathrm{m}$ & $1.6 \mathrm{~mm}$ & & \\
\hline $100 \mu \mathrm{m}$ & $10 \mathrm{~mm}$ & & \\
\hline $20 \mu \mathrm{m}$ & $500 \mu \mathrm{m}$ & & \\
\hline $60 \mu \mathrm{m}$ & $1 \mathrm{~mm}$ & & \\
\hline $4 \mathrm{~mm}$ & $1 \mathrm{~m}$ & \multirow{11}{*}{$\begin{array}{l}\text { Balmuccia peridotite, } \\
\text { Italian Alps }\end{array}$} & \multirow{11}{*}{ Ferrand et al. (2018) } \\
\hline $3 \mathrm{~mm}$ & $20 \mathrm{~cm}$ & & \\
\hline $12 \mu \mathrm{m}$ & $2 \mathrm{~cm}$ & & \\
\hline $5 \mathrm{~mm}$ & $1.7 \mathrm{~m}$ & & \\
\hline $100 \mu \mathrm{m}$ & $6 \mathrm{~mm}$ & & \\
\hline $300 \mu \mathrm{m}$ & $2 \mathrm{~cm}$ & & \\
\hline $1 \mathrm{~mm}$ & $5 \mathrm{~cm}$ & & \\
\hline $10 \mu \mathrm{m}$ & $100 \mu \mathrm{m}$ & & \\
\hline $5 \mu \mathrm{m}$ & $200 \mu \mathrm{m}$ & & \\
\hline $6 \mu \mathrm{m}$ & $300 \mu \mathrm{m}$ & & \\
\hline $20 \mu \mathrm{m}$ & $400 \mu \mathrm{m}$ & & \\
\hline
\end{tabular}

This article is protected by copyright. All rights reserved. 


\begin{tabular}{|c|c|c|c|}
\hline $30 \mu \mathrm{m}$ & $500 \mu \mathrm{m}$ & & \\
\hline $10 \mu \mathrm{m}$ & $300 \mu \mathrm{m}$ & & \\
\hline $6.9 \mathrm{~mm}$ & $54 \mathrm{~cm}$ & \multirow{8}{*}{ Adamello tonalite, Italian Alps } & \multirow{8}{*}{ Di Toro et al. (2006) } \\
\hline $2 \mathrm{~mm}$ & $42.5 \mathrm{~cm}$ & & \\
\hline $1.5 \mathrm{~mm}$ & $34 \mathrm{~cm}$ & & \\
\hline $0.5 \mathrm{~mm}$ & $12 \mathrm{~cm}$ & & \\
\hline $7 \mathrm{~mm}$ & $66 \mathrm{~cm}$ & & \\
\hline $2 \mathrm{~mm}$ & $50 \mathrm{~cm}$ & & \\
\hline $2 \mathrm{~mm}$ & $25 \mathrm{~cm}$ & & \\
\hline $5.9 \mathrm{~mm}$ & $1.44 \mathrm{~m}$ & & \\
\hline $150 \mu \mathrm{m}$ & $2 \mathrm{~mm}$ & \multirow{2}{*}{ Alpine Corsica peridotite } & \multirow{2}{*}{ Andersen et al. (2014) } \\
\hline $1.29 \mathrm{~cm}$ & $90 \mathrm{~cm}$ & & \\
\hline $5 \mathrm{~mm}$ & $3 \mathrm{~m}$ & \multirow{2}{*}{ Balmuccia peridotite } & \multirow{2}{*}{ Obata \& Karato (1995) } \\
\hline $2 \mathrm{~cm}$ & $3 \mathrm{~m}$ & & \\
\hline $0.5 \mathrm{~mm}$ & $5 \mathrm{~mm}$ & \multirow{10}{*}{$\begin{array}{c}\text { Tucker Hill } \\
\text { quartzo-feldspathic schist, } \\
\text { Central Otago, New Zealand }\end{array}$} & \multirow{10}{*}{ Barker (2005) } \\
\hline $750 \mu \mathrm{m}$ & $1.5 \mathrm{~cm}$ & & \\
\hline $2 \mathrm{~mm}$ & $3 \mathrm{~cm}$ & & \\
\hline $3 \mathrm{~mm}$ & $5 \mathrm{~cm}$ & & \\
\hline $3.25 \mathrm{~mm}$ & $6 \mathrm{~cm}$ & & \\
\hline $4 \mathrm{~mm}$ & $7 \mathrm{~cm}$ & & \\
\hline $5 \mathrm{~mm}$ & $9 \mathrm{~cm}$ & & \\
\hline $5 \mathrm{~mm}$ & $11 \mathrm{~cm}$ & & \\
\hline $6 \mathrm{~mm}$ & $14 \mathrm{~cm}$ & & \\
\hline $2 \mathrm{~cm}$ & $20 \mathrm{~cm}$ & & \\
\hline $500 \mu \mathrm{m}$ & $7 \mathrm{~mm}$ & \multirow{19}{*}{$\begin{array}{l}\text { Outer Hebrides gneiss, } \\
\text { Scotland }\end{array}$} & \multirow{14}{*}{ Sibson (1975) } \\
\hline $200 \mu \mathrm{m}$ & $3.4 \mathrm{~mm}$ & & \\
\hline $1.25 \mathrm{~mm}$ & $2.8 \mathrm{~cm}$ & & \\
\hline $500 \mu \mathrm{m}$ & $1.8 \mathrm{~cm}$ & & \\
\hline $1.5 \mathrm{~mm}$ & $6.7 \mathrm{~cm}$ & & \\
\hline $1.75 \mathrm{~mm}$ & $8.8 \mathrm{~cm}$ & & \\
\hline $1.5 \mathrm{~mm}$ & $8.2 \mathrm{~cm}$ & & \\
\hline $1.25 \mathrm{~mm}$ & $7.1 \mathrm{~cm}$ & & \\
\hline $1 \mathrm{~mm}$ & $5.8 \mathrm{~cm}$ & & \\
\hline $2 \mathrm{~mm}$ & $11.7 \mathrm{~cm}$ & & \\
\hline $750 \mu \mathrm{m}$ & $6.8 \mathrm{~cm}$ & & \\
\hline $2.25 \mathrm{~mm}$ & $24,3 \mathrm{~cm}$ & & \\
\hline $7.5 \mathrm{~mm}$ & $1.29 \mathrm{~m}$ & & \\
\hline $3.25 \mathrm{~mm}$ & $91 \mathrm{~cm}$ & & \\
\hline $300 \mu \mathrm{m}$ & $2.2 \mathrm{~cm}$ & & \multirow{5}{*}{ Nielsen et al. (2010b) } \\
\hline $1.1 \mathrm{~mm}$ & $2.4 \mathrm{~cm}$ & & \\
\hline $650 \mu \mathrm{m}$ & $1.2 \mathrm{~cm}$ & & \\
\hline $1.35 \mathrm{~mm}$ & $5.5 \mathrm{~cm}$ & & \\
\hline $400 \mu \mathrm{m}$ & $3.1 \mathrm{~cm}$ & & \\
\hline
\end{tabular}

This article is protected by copyright. All rights reserved. 


\begin{tabular}{|l|l|}
\hline $180 \mu \mathrm{m}$ & $2.6 \mathrm{~cm}$ \\
\hline $1.4 \mathrm{~mm}$ & $8.0 \mathrm{~cm}$ \\
\hline $450 \mu \mathrm{m}$ & $2.5 \mathrm{~cm}$ \\
\hline $800 \mu \mathrm{m}$ & $1.8 \mathrm{~cm}$ \\
\hline $800 \mu \mathrm{m}$ & $6.5 \mathrm{~cm}$ \\
\hline $1.4 \mathrm{~mm}$ & $7.5 \mathrm{~cm}$ \\
\hline $400 \mu \mathrm{m}$ & $4.3 \mathrm{~cm}$ \\
\hline $300 \mu \mathrm{m}$ & $6.5 \mathrm{~cm}$ \\
\hline $600 \mu \mathrm{m}$ & $5.7 \mathrm{~cm}$ \\
\hline $3.1 \mathrm{~mm}$ & $42 \mathrm{~cm}$ \\
\hline $2.8 \mathrm{~mm}$ & $63 \mathrm{~cm}$ \\
\hline $1.93 \mathrm{~mm}$ & $48 \mathrm{~cm}$ \\
\hline $1.63 \mathrm{~mm}$ & $7.8 \mathrm{~cm}$ \\
\hline $430 \mu \mathrm{m}$ & $4.9 \mathrm{~cm}$ \\
\hline $1.3 \mathrm{~mm}$ & $9.4 \mathrm{~cm}$ \\
\hline $670 \mu \mathrm{m}$ & $8.2 \mathrm{~cm}$ \\
\hline $1.8 \mathrm{~mm}$ & $15 \mathrm{~cm}$ \\
\hline $1.44 \mathrm{~mm}$ & $31 \mathrm{~cm}$ \\
\hline $630 \mu \mathrm{m}$ & $5.9 \mathrm{~cm}$ \\
\hline $1.25 \mathrm{~mm}$ & $27.5 \mathrm{~cm}$ \\
\hline $2.75 \mathrm{~mm}$ & $68.5 \mathrm{~cm}$ \\
\hline $400 \mu \mathrm{m}$ & $3.5 \mathrm{~cm}$ \\
\hline $530 \mu \mathrm{m}$ & $4.3 \mathrm{~cm}$ \\
\hline $550 \mu \mathrm{m}$ & $4.1 \mathrm{~cm}$ \\
\hline $720 \mu \mathrm{m}$ & $7.6 \mathrm{~cm}$ \\
\hline $700 \mu \mathrm{m}$ & $12 \mathrm{~cm}$ \\
\hline $300 \mu \mathrm{m}$ & $4.6 \mathrm{~cm}$ \\
\hline $470 \mu \mathrm{m}$ & $1.1 \mathrm{~cm}$ \\
\hline $1.8 \mathrm{~mm}$ & $1.67 \mathrm{~m}$ \\
\hline $300 \mu \mathrm{m}$ & $2.2 \mathrm{~cm}$ \\
\hline
\end{tabular}

This article is protected by copyright. All rights reserved. 
Table 2 - Dataset from rotary-shear experiments presented in Fig. 2.

\begin{tabular}{|c|c|c|c|c|c|}
\hline$a^{*}$ or $w^{*}$ & $\boldsymbol{D}$ & Normal stress & Slip speed & Material & Reference \\
\hline$a^{*}(\mathrm{~mm})$ & $D(\mathrm{~m})$ & \multicolumn{4}{|c|}{ Rotary-shear experiments (Final melt thickness $a^{*}$ as a function of slip) } \\
\hline 0,033 & 24,5 & \multirow{6}{*}{ 1.2-1.4 MPa } & \multirow{6}{*}{$0.85 \mathrm{~m} . \mathrm{s}^{-1}$} & \multirow{6}{*}{ Gabbro, India } & \multirow{6}{*}{$\begin{array}{l}\text { Hirose \& Shimamoto } \\
\text { (2005a \& 2005b) }\end{array}$} \\
\hline 0,084 & 30,8 & & & & \\
\hline 0,104 & 38,5 & & & & \\
\hline 0,116 & 46,8 & & & & \\
\hline 0,108 & 57,7 & & & & \\
\hline 0,135 & 78,6 & & & & \\
\hline 0,0659 & 1,53 & \multirow{6}{*}{$13 \mathrm{MPa}$} & \multirow{6}{*}{$1.14 \mathrm{~m} \cdot \mathrm{s}^{-1}$} & \multirow{6}{*}{$\begin{array}{l}\text { Balmuccia peridotite, } \\
\text { Italy }\end{array}$} & \multirow{6}{*}{$\begin{array}{l}\text { Del Gaudio et al. } \\
(2009)\end{array}$} \\
\hline 0,1265 & 2,77 & & & & \\
\hline 0,0384 & 5,7 & & & & \\
\hline 0,0498 & 9,9 & & & & \\
\hline 0,1311 & 30,5 & & & & \\
\hline 0,112 & 31,31 & & & & \\
\hline$w^{*}(\mathrm{~mm})$ & $D(\mathrm{~m})$ & \multicolumn{4}{|c|}{ Rotary-shear experiments (axial shortening $\mathrm{w}^{*}$ as a function of slip) } \\
\hline 3 & 6 & \multirow{5}{*}{$20 \mathrm{MPa}$} & \multirow{5}{*}{$3 \mathrm{~m} \cdot \mathrm{s}^{-1}$} & \multirow{19}{*}{$\begin{array}{l}\text { quartz microgabbro } \\
\text { "Absolute black" }\end{array}$} & \multirow{5}{*}{$\begin{array}{l}\text { Niemeijer et al. } \\
\text { (2011), Fig. } 5\end{array}$} \\
\hline 2.3 & 5 & & & & \\
\hline 1.7 & 4 & & & & \\
\hline 1 & 3 & & & & \\
\hline 0.5 & 2 & & & & \\
\hline 2 & 1 & \multirow{6}{*}{$20 \mathrm{MPa}$} & \multirow{3}{*}{$1 \mathrm{~m} \cdot \mathrm{s}^{-1}$} & & \multirow{10}{*}{$\begin{array}{l}\text { Niemeijer et al. } \\
\text { (2011), Fig. } 8 \\
\text { SHIVA, Rome, Italy }\end{array}$} \\
\hline 1 & 0.5 & & & & \\
\hline 4 & 2 & & & & \\
\hline 0.5 & 1 & & \multirow{3}{*}{$3 \mathrm{~m} \cdot \mathrm{s}^{-1}$} & & \\
\hline 0.25 & 0.5 & & & & \\
\hline 1 & 2 & & & & \\
\hline 0.45 & 10 & \multirow{8}{*}{$10 \mathrm{MPa}$} & \multirow{8}{*}{$1.3 \mathrm{~m} \cdot \mathrm{s}^{-1}$} & & \\
\hline 0.3 & 8 & & & & \\
\hline 0.2 & 6 & & & & \\
\hline 0,1 & 4 & & & & \\
\hline 1.4 & 10 & & & & \multirow{4}{*}{$\begin{array}{l}\text { Niemeijer et al. } \\
\text { (2011), Fig. } 9 \\
\text { HV-1, Kochi, Japan }\end{array}$} \\
\hline 0.9 & 8 & & & & \\
\hline 0.4 & 6 & & & & \\
\hline 0.1 & 4 & & & & \\
\hline 0.75 & 1 & \multirow{4}{*}{$15 \mathrm{MPa}$} & \multirow{4}{*}{$1.28 \mathrm{~m} \cdot \mathrm{s}^{-1}$} & \multirow{4}{*}{$\begin{array}{l}\text { Adamello tonalite } \\
\text { Italian Alps }\end{array}$} & \multirow{4}{*}{$\begin{array}{l}\text { Di Toro et al. } \\
\text { (2006), Fig. } 2 \\
\text { SHIVA, Rome, Italy }\end{array}$} \\
\hline 0.9 & 2 & & & & \\
\hline 1.3 & 3 & & & & \\
\hline 1.5 & 4 & & & & \\
\hline
\end{tabular}

This article is protected by copyright. All rights reserved. 